\title{
Validation of cloud property retrievals with simulated satellite radiances: a case study for SEVIRI
}

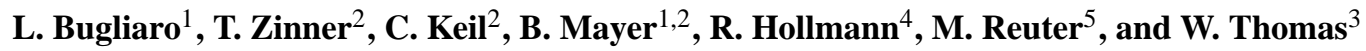 \\ ${ }^{1}$ Deutsches Zentrum für Luft- und Raumfahrt, Institut für Physik der Atmosphäre, Oberpfaffenhofen, Germany \\ ${ }^{2}$ Meteorologisches Institut, Ludwig-Maximilians-Universität, Munich, Germany \\ ${ }^{3}$ Deutscher Wetterdienst, Meteorologisches Observatorium Hohenpeissenberg, Hohenpeissenberg, Germany \\ ${ }^{4}$ Deutscher Wetterdienst, Department Climate Monitoring, Satellite Application Facility on Climate Monitoring, \\ Offenbach am Main, Germany \\ ${ }^{5}$ Institute of Environmental Physics, University of Bremen, FB1, Bremen, Germany
}

Received: 28 July 2010 - Published in Atmos. Chem. Phys. Discuss.: 21 September 2010

Revised: 12 May 2011 - Accepted: 18 May 2011 - Published: 17 June 2011

\begin{abstract}
Validation of cloud properties retrieved from passive spaceborne imagers is essential for cloud and climate applications but complicated due to the large differences in scale and observation geometry between the satellite footprint and the independent ground based or airborne observations. Here we illustrate and demonstrate an alternative approach: starting from the output of the COSMOEU weather model of the German Weather Service realistic three-dimensional cloud structures at a spatial scale of $2.33 \mathrm{~km}$ are produced by statistical downscaling and microphysical properties are associated to them. The resulting data sets are used as input to the one-dimensional radiative transfer model libRadtran to simulate radiance observations for all eleven low resolution channels of MET-8/SEVIRI. At this point, both cloud properties and satellite radiances are known such that cloud property retrieval results can be tested and tuned against the objective input "truth". As an example, we validate a cloud property retrieval of the Institute of Atmospheric Physics of DLR and that of EUMETSAT's Climate Monitoring Science Application Facility CMSAF. Cloud detection and cloud phase assignment perform well. By both retrievals $88 \%$ of the pixels are correctly classified as clear or cloudy. The DLR algorithm assigns the correct thermodynamic phase to $95 \%$ of the cloudy pixels and the CMSAF retrieval to $84 \%$. Cloud top temperature is slightly overestimated by the DLR code $(+3.1 \mathrm{~K}$ mean difference with a standard deviation of $10.6 \mathrm{~K}$ ) and to a very low extent by the CMSAF code $(-0.12 \mathrm{~K}$ with a standard deviation of $7.6 \mathrm{~K})$.
\end{abstract}

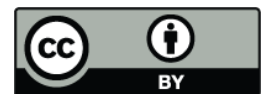

Correspondence to: L. Bugliaro (luca.bugliaro@dlr.de)
Both retrievals account reasonably well for the distribution of optical thickness for both water and ice clouds, with a tendency to underestimation. Cloud effective radii are most difficult to evaluate but the APICS algorithm shows that realistic histograms of occurrences can be derived (CMSAF was not evaluated in this context). Cloud water path, which is a combination of the last two quantities, is slightly underestimated by APICS, while CMSAF shows a larger scattering.

\section{Introduction}

The determination of cloud macrophysical (e.g. cloud top height), optical (e.g. cloud optical thickness) as well as microphysical (e.g. cloud phase or cloud effective particle radius) is essential for various applications and in general for a deep understanding of cloud and climate processes. For this reason, validation of satellite retrieved cloud properties is crucial. Validation is complicated, however, by the lack of comparable and independent cloud observations. A series of passive imagers like the Advanced Very High Resolution Radiometer AVHRR, the Advanced Along-Track Scanning Radiometer AATSR, the Moderate Resolution Imaging Spectroradiometer MODIS, and the Spinning Enhanced Visible and Infrared Imager SEVIRI are routinely used to derive macrophysical, microphysical, and optical properties of clouds from polar or geostationary orbits with various spatial and temporal resolutions. Cloud classification algorithms developed for these instruments are usually based on heuristic threshold tests. Independent objective methods to derive cloud properties are often not available, as satellite

Published by Copernicus Publications on behalf of the European Geosciences Union. 
observations are the only means to observe clouds on a grand scale. Recently, the advent of the A-Train with its five Earth Observing satellites flying in formation has opened new perspectives for validation purposes. In particular, the simultaneous use of lidar, radar and imager has lead to a variety of publications (see for instance the Special Section "Aerosol and Cloud Studies From CALIPSO and the A-Train" of the Journal of Geophysical Research, volumes 114 and 115, in 2009 and 2010). However, also with this satellite constellation the state of the atmosphere is only partially known and its characterisation still rests upon various assumptions made by the different (sophisticated) spaceborne retrievals. Of course, when comparing satellite retrievals with each other interesting aspects can be identified and potential algorithmic defects can be highlighted by considering the agreement or disagreement of the retrievals. Nevertheless, this does not at all enable an objective and quantitative validation of the derived cloud properties.

Cloud observations from the surface are a possible independent data source for validation, but we know that, in addition to the just mentioned variety of retrievals and related assumptions, systematic differences are to be expected due to the different scales of the surface and the satellite measurements (e.g. Schutgens and Roebeling, 2009). For cloud microphysical properties like cloud phase or particle size, the situation is even worse: only sparse in-situ data, measured by aircraft, are available. To get any estimates of cloud microphysical properties from the ground, a complex combination of instruments is required to obtain quantitative results (e.g. microwave radiometry, radar, lidar). In addition, three dimensional radiative effects and cloud inhomogeneity introduce some bias and considerable noise into the optical thickness and effective radius retrieved at the resolutions of the order 1-5 km (e.g., Zinner and Mayer, 2006). Although one could live with a small bias, noise hampers the validation by in-situ observations, as many data are needed to obtain a statistically significant result. This is usually not the case due to the limited availability of such data sets or due to the rarity of satellite overpasses over the validation sites.

Thus, we propose and demonstrate an alternative strategy: starting from a known cloud field, the satellite observation has been simulated to produce data sets where radiation as well as cloud properties are fully known, in contrast to the use of satellite observations alone where only the radiation field is available and the accuracy of the derived cloud information cannot be assessed because the "real" cloud properties are not known. On this basis, retrieval algorithms can be tested and tuned, by comparing the retrieved properties with the initial cloud properties. In this paper we simulate a MET-8/SEVIRI scene in Central Europe. To this end, we exploit the output of the weather model COSMO-EU to produce realistic three-dimensional cloud fields at a resolution of $7 \mathrm{~km}$ of mesoscale size. Since the resolution is too coarse for a simulation of the envisaged satellite instrument we apply a downscaling technique to obtain the necessary input data for the radiative transfer calculations at a more suitable spatial resolution of $2.33 \mathrm{~km}$. The satellite radiances are produced with the one-dimensional radiative transfer solver DISORT 2.0 as part of the radiative transfer package libRadtran. The radiative transfer output (i.e. the eleven solar and thermal MET-8/SEVIRI channels) for that particular scene is then used as input to two cloud retrieval algorithms to exemplarily show the potential of the method to objectively test and evaluate the retrieval performance.

Simulation of measurements of passive space-borne imaging radiometers can be achieved by means of detailed radiative transfer models and is a powerful and useful tool to answer many kinds of questions. For instance, look-up tables of satellite radiances in the visible and near-infrared can be used to determine cloud optical thickness and cloud particle effective radius of water and ice clouds (Nakajima and King, 1990). Simulated radiances in infrared spectral bands are used to determine cloud top height when the background atmospheric profiles of temperature, pressure and gas concentrations are known (Schmetz et al., 1993; Smith et al., 1970; Smith and Platt, 1978; Menzel et al., 1983). Retrievals of surface skin temperature (Wan and Dozier, 1996; Wan and $\mathrm{Li}, 1997$ ) also need detailed radiative transfer calculations to account for the effect of the atmosphere on the measured infrared signals. Extensive radiative transfer computations have been also adopted to investigate the behaviour of satellite signals or retrievals as a function of various parameters. Clerbaux et al. (2003) study the angular dependency of satellite infrared radiances on viewing angle. Krebs et al. (2007) assess the performance of a cirrus detection algorithm. Mayer et al. (2011) relate solar SEVIRI radiances to top-of-atmosphere broadband irradiances. Ham et al. (2009) investigate the capability of MODIS cloud products to reproduce the measured MODIS radiances in 15 bands. Kokhanovsky et al. (2010) compare four aerosol optical thickness retrieval algorithms using systematic simulations of synthetic top-of-atmosphere solar backscattered radiation. Finally, numerical weather prediction model output has been used to simulate future satellite sensor top-ofatmosphere radiances and to demonstrate the novel instruments' advanced capabilities (e.g., Otkin et al. (2007)). Most of these investigations use radiative transfer models with the aim of either producing a statistically significant data set of satellite radiances or of systematically characterising the possible range of top-of-atmosphere radiance measurements. Only a few yield spatially extended simulated thermal band radiances and none of them generates realistic satellite scenes for all solar and thermal channels of a passive imager instrument, as we do in this paper. In addition, we use accurate one dimensional radiative transfer simulations and employ no parameterisation of the photon transport. Finally, and most importantly, we show here for the first time the combination of downscaling of numerical weather prediction model output with detailed radiative transfer calculations for the generation of a realistic and complete satellite scene that is used in 
Table 1. SEVIRI spectral channels characteristics (Schmetz et al., 2002).

\begin{tabular}{lcccc}
\hline Channel & $\lambda_{\text {central }}$ & $\lambda_{\min }$ & $\lambda_{\max }$ & $\begin{array}{c}\text { Spatial } \\
\text { Resolution } \\
\text { km }\end{array}$ \\
\hline VIS006 & 0.635 & 0.56 & 0.71 & 3 \\
VIS008 & 0.81 & 0.74 & 0.88 & 3 \\
IR_016 & 1.64 & 1.50 & 1.78 & 3 \\
IR_039 & 3.90 & 3.48 & 4.36 & 3 \\
WV_062 & 6.25 & 5.35 & 7.15 & 3 \\
WV_073 & 7.35 & 6.85 & 7.85 & 3 \\
IR_087 & 8.70 & 8.30 & 9.10 & 3 \\
IR_097 & 9.66 & 9.38 & 9.94 & 3 \\
IR_108 & 10.80 & 9.80 & 11.80 & 3 \\
IR_120 & 12.00 & 11.00 & 13.00 & 3 \\
IR_134 & 13.40 & 12.40 & 14.40 & 3 \\
HRV & Broadband (about $0.4-1.1)$ & 1 \\
\hline
\end{tabular}

its turn for the quantitative validation of cloud property retrievals.

The paper is structured as follows: after a short description of the satellite instrument MET-8/SEVIRI selected for this investigation (Sect. 2), the cloud and radiative transfer models (Sect. 3) are presented. Section 4 shows the results of the radiative transfer simulations while Sect. 5 illustrates the retrieval algorithms and Sect. 6 the validation of the retrieval outputs by comparison with the known input cloud properties. Conclusions are found in Sect. 7 together with a discussion of peculiarities and limitations of the proposed method.

\section{MET-8/SEVIRI: a case study}

The second generation of the geostationary Meteosat satellites operated by EUMETSAT represents a great advancement compared to the first generation, for the imaging and remote sensing of the Earth's atmosphere and surface and the related physical processes. In particular, the Spinning Enhanced Visible and InfraRed Imager (SEVIRI) aboard Meteosat Second Generation (MSG) combines a fast repeat cycle of $15 \mathrm{~min}$ with comprehensive spectral information over the whole Earth disc (see Table 1). SEVIRI comprises 11 spectral channels in the visible and infrared spectral range with a spatial resolution of $3 \mathrm{~km} \times 3 \mathrm{~km}$ at the sub-satellite point. Furthermore, it is equipped with an additional broadband high resolution visible (HRV) channel with a ground sampling distance of about $1 \mathrm{~km}$ at the sub-satellite point. This resolution is comparable to that of the polar orbiting NOAA/AVHRR radiometers $(1.1 \mathrm{~km}$ at nadir) from which SEVIRI has adopted some of its spectral channels. This series of satellite instruments has proved to yield data that are excellently suited for meteorological and geophysical appli- cations. Considering also the improved dynamic range of 10 (instead of 8) bits, it is clear that MSG/SEVIRI allows to quantitatively study the life cycle of clouds in a unique way. MSG-1, launched in August 2002 into the geostationary orbit at $-3.4^{\circ} \mathrm{E}$, is the satellite selected for this case study. The SEVIRI sensor on it became operational January 2004 under the name of MET-8/SEVIRI.

\section{Models}

In order to create a synthetic satellite scene two ingredients are needed: (1) a model to produce realistic cloud fields to be used as input for (2) an accurate radiative transfer model to simulate the MET-8/SEVIRI low resolution channels. Both models are presented in the following subsections.

\subsection{Cloud model}

\subsubsection{The COSMO-EU model}

For the generation of realistic cloud fields over regions as large as to encompass a considerable variability of cloud as well as surface properties, the output of the COSMOEU model (version 3.15) of the COSMO (COnsortium for Small-scale MOdeling) community has been used. The COSMO-EU is a high-resolution non-hydrostatic model (Steppeler et al., 1997) that has been the operational short range weather forecasting tool at the German Weather Service (Deutscher Wetterdienst, DWD) since December 1999. In the operational configuration, with a horizontal mesh size of $7 \mathrm{~km}$ on a $325 \times 325$ grid, the model domain encompasses all of Central Europe. It has a generalised terrain-following vertical coordinate, which divides the atmosphere into 35 layers from the bottom up to $20 \mathrm{hPa}$. The prognostic model variables are the wind vector, temperature, pressure perturbation, specific humidity, cloud liquid and ice water, rain and snow water. The model physics includes a level-2 turbulence parameterisation, a delta-2-stream radiation scheme, and a multi-layer soil model. The model contains a grid-scale cloud and precipitation scheme as well as a parameterisation of moist convection (Tiedtke, 1989).

The COSMO-EU vertical profiles used are pressure, temperature, specific humidity, cloud liquid water, cloud ice and snow water together with skin temperature, orography and the land-sea mask. In particular, snow water is associated to ice water because the large autoconversion rates used in the COSMO-EU lead to an under-representation of ice clouds.

As a validation scene for the cloud property retrieval algorithm we selected 12 August 2004, 12:00 UTC, where a frontal system is passing through Central Europe and various cloud types are present. 
(a)
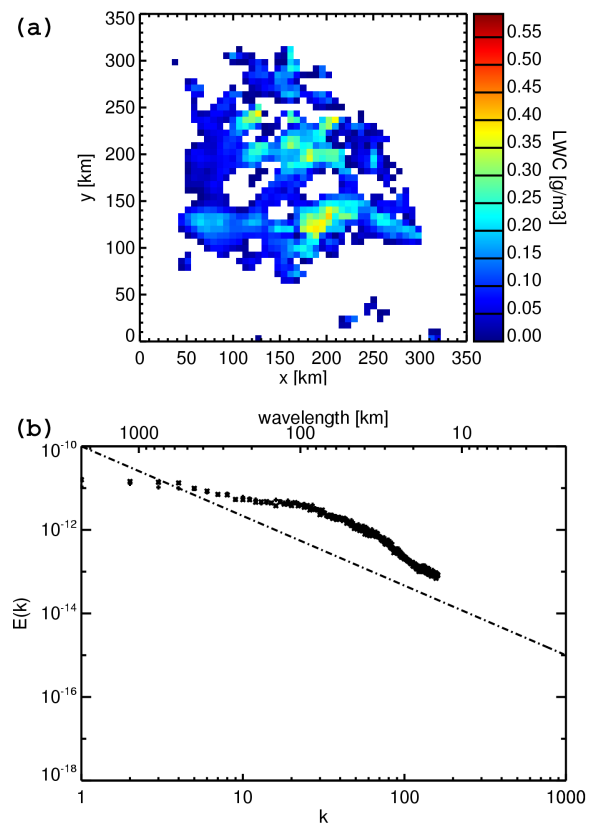

(c)
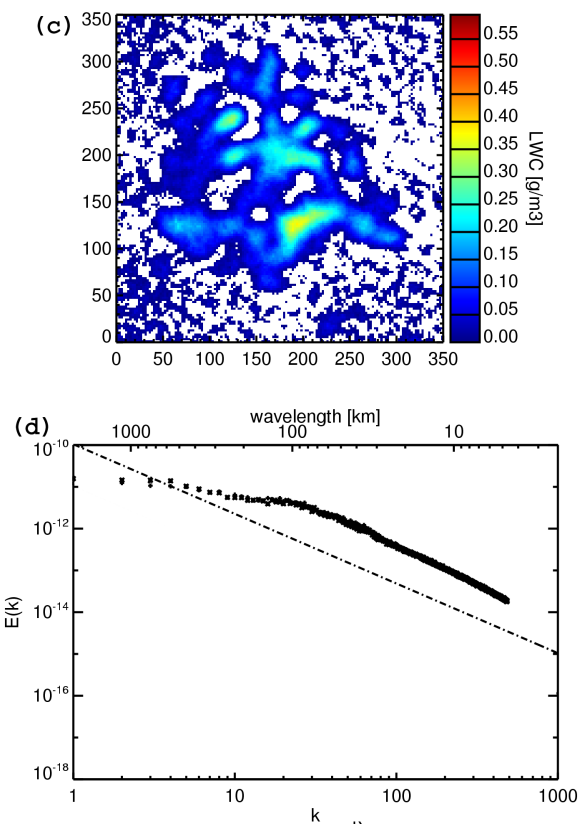

(e)
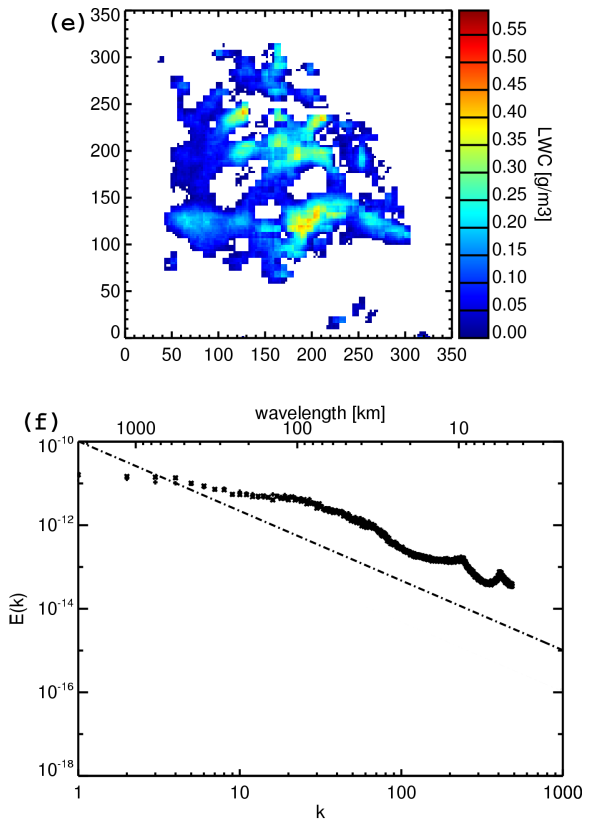

Fig. 1. Downscaling of a layer of LWC from the COSMO-EU model: Shown is a water content field of a certain height level from COSMOEU (a) through the iteration steps (c) leading to the final downscaled field (e). Through the process negative LWC values are allowed (reflected by the spurious positive water content values in dark blue throughout the cloud free areas in (c)). All these values are set to zero in (e). (b), (d), and (f) show the related power spectra.

\subsubsection{Downscaling}

As the COSMO-EU model, like all weather models, does not provide information on scales below a few kilometres (more precisely $7 \mathrm{~km}$ for COSMO-EU), statistical downscaling is applied as a possibility to merge the potential of weather models to provide realistic mesoscale cloud structures in three dimensions and the potential of statistical models to generate realistic small scale variability on the basis of observed statistical characteristics of Liquid Water Content (LWC) fields (down to $10 \mathrm{~m}$ scale, e.g. Davis, 1996). Venema et al. (2010) use a method similar to the one presented in the following for the downscaling of cloud resolving large eddy simulation model output. A better spatial resolution is mandatory to create input data as realistic as possible in order to assess retrieval performance under real-world conditions.

First, the generalised terrain-following vertical coordinate is transformed to metric coordinates: while temperature and pressure are appropriately interpolated, the other quantities of interest (cloud liquid and ice water, snow water) are mapped such as to preserve the information on the original COSMO-EU vertical resolution and their integrated vertical column. At the same time vertical resolution is increased: $\Delta z=250 \mathrm{~m}$ up to $5000 \mathrm{~m}$ a.s.l. and $\Delta z=550 \mathrm{~m}$ up to $21500 \mathrm{~m}$ a.s.l. All data sets are now given on a regular vertical grid with 50 layers. The horizontal resolution is still unchanged.
Starting from the original horizontal resolution of approximately $7 \mathrm{~km}$ corresponding to $325 \times 325$ pixels, the resolution of the main output quantities of the COSMO-EU is increased to $2.33(=7 / 3) \mathrm{km}$. During this procedure the energy density (the Fourier spectrum) of the water fields is forced to obey a $5 / 3$ decay law for small scale variations ("sub-resolution" in the following), as shown by many in-situ measurements (e.g. Davis, 1996; Pinsky and Khain, 2003) while large scale variation and the water content on the original horizontal resolution $(7 \mathrm{~km})$ is conserved.

This downscaling algorithm starts with the cloud layer closest to the ground and proceeds, layer by layer, towards cloud top. Variations in the lowest layer are less constrained than in upper layers because vertical correlation of the subgrid variations is imposed. The exact parameters are freely chosen to best complement the resolved vertical and horizontal correlation on the original COSMO-EU scale for this scene. Step by step the 5/3 Fourier power spectrum is forced on the sub-resolution cloud water fields while the total content at the COSMO-EU resolution as given in the COSMOEU output is conserved. The Fourier spectrum of the original COSMO-EU fields is thus conserved on large scales, while variability at small scales is introduced by continuation of the $5 / 3$ power spectrum below a given wavenumber depending on the size of the COSMO-EU simulation domain.

The phase of the small scale Fourier components of the bottom layer is created randomly while the large scale (COSMO-EU modelled) phases are conserved. Vertical 
correlation of sub-resolution variations is achieved by retaining part of the small scale Fourier phases whenever the algorithm switches to a higher layer. In each of these layers only the highest frequency phases are randomly selected. This way a vertical correlation is generated on the vertical subresolution scale which best interpolates between the resolved low resolution vertical variations.

Figure 1a shows a sub-section of the COSMO-EU input data. Shown is a horizontal cross section through the liquid water content of $350 \times 350 \mathrm{~km}^{2}$ (at $7 \mathrm{~km}$ resolution) at the height layer between 1500 and $1750 \mathrm{~m}$. The related power spectrum is displayed below it. Obviously it shows no clear scaling law behaviour. While at large scales (small wavenumbers) the mesoscale weather structures are not expected to do so, a $5 / 3$ power law is expected at ranges between $10-30 \mathrm{~km}(k \approx 60-100)$ down to a few metres. In the original COSMO-EU data a $5 / 3$ power law scaling seems to be present down to a wavelength range of $30 \mathrm{~km}$.

Next a new Fourier spectrum is constructed from the large scale amplitudes (up to $k=80$ ) with small scale amplitudes (smaller than $30 \mathrm{~km}$ ) obtained according to a $5 / 3$ power law up to wavenumbers of $k=486$ (according to a wavelength of $2 \times 2.33 \mathrm{~km}$ ). Using these new amplitudes (and related random phases) a new two-dimensional field of liquid water content for this layer is constructed by a backward Fourier transform on an increased horizontal resolution (Fig. 1c). As this new fields does not obey the original liquid water content on $7 \mathrm{~km}$ resolution each Fourier step is followed by a step restoring this requisite. Figure 1e shows the resulting field of liquid water content after 3 iteration steps. The Fourier spectrum is not perfect (Fig. 1f) due to the requirement of conserving the $7 \mathrm{~km}$ COSMO-EU-scale LWC distribution. This introduces discontinuities as the cloud gaps and also the block structure reflecting the original resolution. Nonetheless, a field matching the COSMO-EU weather model cloud physics on COSMO-EU resolution comprising statistically realistic small scale variability is generated.

Finally, atmospheric profiles from the COSMO-EU are extended to $120 \mathrm{~km}$ using the standard AFGL midlatitude summer atmosphere (Anderson et al., 1986). Trace gases not contained in the COSMO-EU output, in particular ozone, are also taken from this standard profile.

All final input fields have thus a resolution of $2.33 \mathrm{~km}$ and are given on a $972 \times 972 \times 50$ grid (Fig. 2 f). This way a scene of the size of Central Europe is generated with large structures of real weather related cloudiness and realistic detail on the small scales. The selected spatial resolution enables the consideration of sub-scale variability in a reasonable way with up to 8 downscaled COSMO-EU columns in a MSG/SEVIRI pixel. In general such a resolution could as well be achieved by utilising the high-resolution COSMODE $(2.8 \mathrm{~km})$. However such a model run alone would not produce realistic variability on the smallest model scales either due to numerical diffusion. In addition, inevitably, the
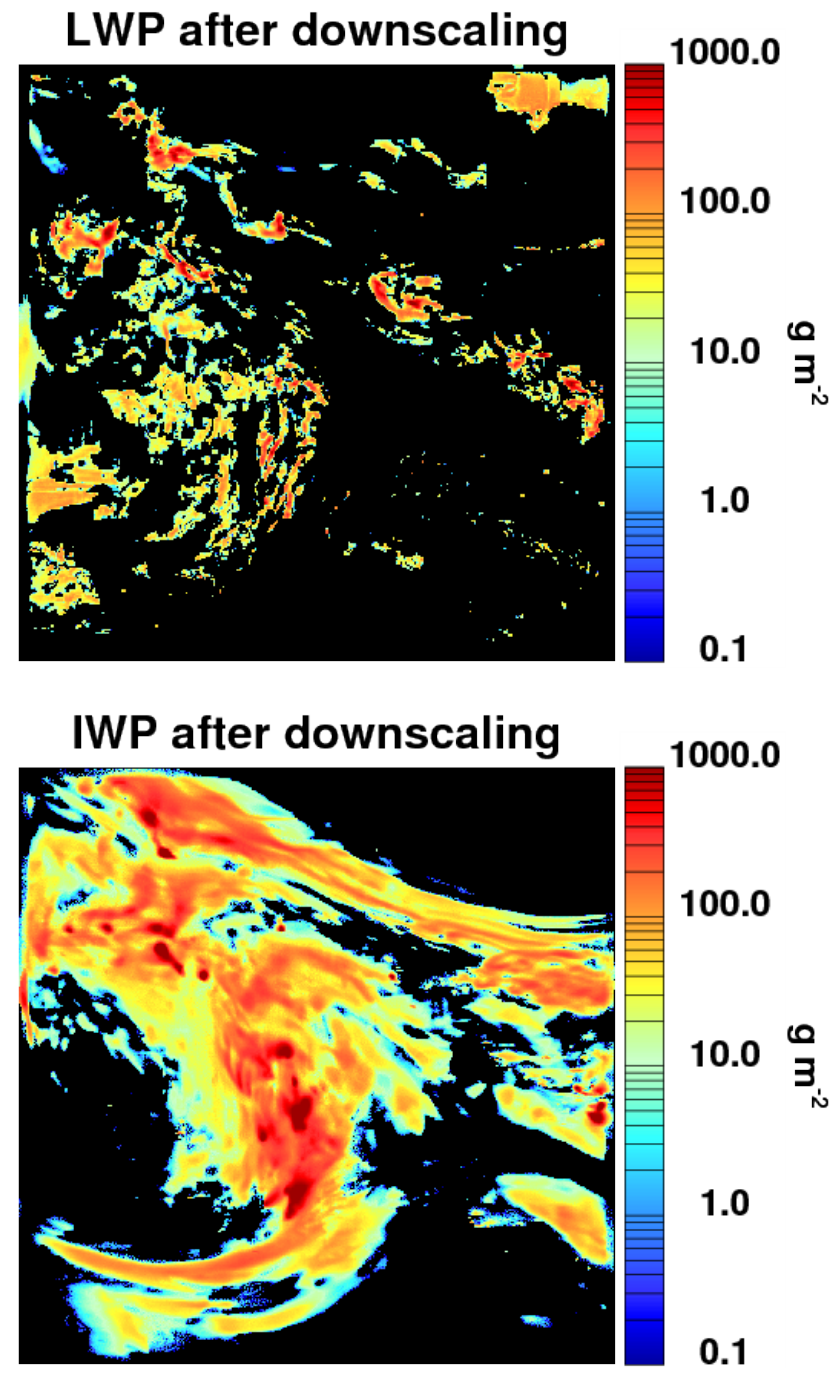

Fig. 2. Cloud liquid (top) and cloud ice water path (bottom) for the COSMO-EU grid after resolution enhancement.

domain size would have had to be much smaller due to computational limits.

\subsubsection{Microphysics}

Once resolution has been enhanced, cloud microphyics has to be associated to the cloud liquid and ice water fields. For water clouds, liquid water content $\mathrm{LWC}\left[\mathrm{kg} / \mathrm{m}^{3}\right]$ and effective radius $r_{\mathrm{eff}}=\int r^{3} n(r) d r / \int r^{2} n(r) d r[\mu \mathrm{m}](n(r)$ is the particle size distribution in droplets $/ \mathrm{m}^{3}$ ) are connected through

$r_{\text {eff }}=\left(0.75 \cdot\left(\frac{\mathrm{LWC}}{\pi \cdot k \cdot N \cdot \rho}\right)\right)^{1 / 3} \times 10^{-6}$.

Water droplet density $N\left[1 / \mathrm{m}^{3}\right]$ must be given (here = $150.0 \mathrm{e} 61 / \mathrm{m}^{3}$ ) and is kept constant for all clouds in the domain. The $k$ factor describes the ratio between the volumetric radius of droplets, i.e. the mean volume radius, $r_{v}=$ 
$\left(\int n(r) r^{3} d r / \int n(r) d r\right)^{1 / 3}=\left(\int n(r) r^{3} d r / N\right)^{1 / 3}$ and their effective radius $r_{\text {eff: }}: k=r_{v}^{3} / r_{\text {eff }}^{3}$ and varies between $0.67 \pm$ 0.07 for continental clouds and $0.8 \pm 0.07$ for marine clouds according to Martin et al. (1994). Here we used a typical value of $k=0.75$. $\rho$ is water density at $4^{\circ} \mathrm{C}$ in $\mathrm{kg} / \mathrm{m}^{3}$.

For ice clouds the parameterisation of randomly oriented hexagonal columns by Wyser and Ström (1998); McFarquhar et al. (2003) is used which relates ice particle effective radius $r_{\text {eff }}[\mu \mathrm{m}]$ to ice water content IWC $\left[\mathrm{kg} / \mathrm{m}^{3}\right]$ and temperature $T[\mathrm{~K}]:$

$b=-2.0+0.001 \cdot(\sqrt{273-T})^{3} \cdot \log \left((\mathrm{IWC} / 1000) /\left(50 \mathrm{~g} / \mathrm{m}^{3}\right)\right)$

$r_{0}=377.4+203.3 \cdot b+37.91 \cdot b^{2}+2.3696 \cdot b^{3}$

$n_{f t}=(\sqrt{3}+4) /(3 \sqrt{3})$

$r_{1}=r_{0} / n_{f t}$

$r_{\text {eff }}=(4 \sqrt{3} / 9) r_{1}$.

\subsection{Radiative transfer model}

In order to simulate satellite images from forecast model fields, a radiative transfer model needs to be applied. We take advantage of the libRadtran package (http://www.libradtran.org). libRadtran (Mayer and Kylling, 2005) has been validated in several model intercomparison campaigns, and by direct comparison with observations (e.g., Mayer et al., 1997; Van Weele et al., 2000; DeBacker et al., 2001). Particular attention has been laid on the detailed and most realistic representation of water and ice clouds in the model. Optical properties of water droplets are computed using Mie theory and tabulated as a function of wavelength and effective radius. Ice crystals are not spherical in shape and no comprehensive theory, as Mie for spheres, can be employed. Thus, the conversion from microphysical to optical properties is much less defined. For this simulation the parameterisation of Key et al. (2002) and Yang et al. (2000) for hexagonal ice columns has been selected since it has an adequate spectral resolution. However, it only covers the solar spectral bands of MET-8/SEVIRI. Thus, starting from new single scattering optical properties provided by P. Yang (personal communication, 2006), we have developed a new parameterisation of scattering and absorption properties covering the complete solar and thermal spectral range between 0.25 and $100 \mu \mathrm{m}$, consistent with that of Key et al. (2002) and Yang et al. (2000) for the solar part of the spectrum. The resulting parameterisation of ice crystal optical properties is thus consistent over the full MET-8/SEVIRI spectral range (Fig. 3). Aerosols also deserve a comprehensive treatment. As default we used the rural aerosol model by Shettle (1989) in the boundary layer, background aerosol above $2 \mathrm{~km}$, spring-summer conditions and a visibility of $50 \mathrm{~km}$.

The selected one-dimensional radiative transfer solver is DISORT 2.0 by Stamnes et al. $(1988,2000)$, with 16 streams. Atmospheric gas absorption has been adopted from SBDART (Ricchiazzi et al., 1998) and relies on low resolution band models developed for the LOWTRAN 7 atmospheric transmission code (Pierluissi and Peng, 1985). It uses an exponential sum fit with a resolution of $20 \mathrm{~cm}^{-1}$. We adopted 15 spectral grid points to simulate each low resolution channel. The HRV channel was not simulated.

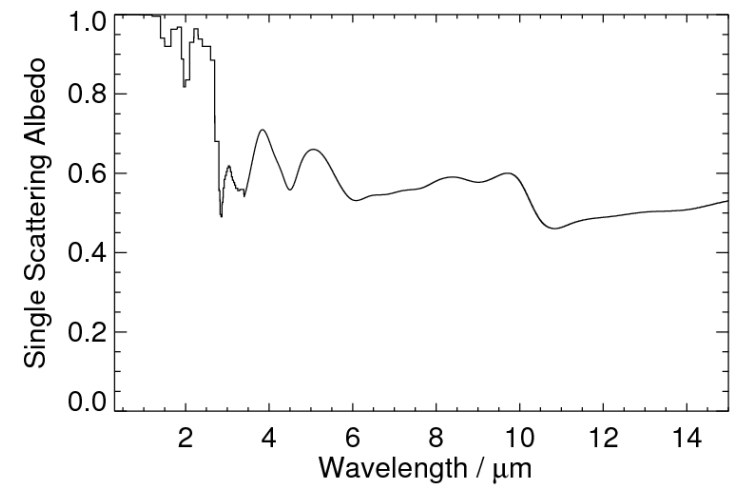

Fig. 3. Single scattering albedo for hexagonal ice crystals of $30 \mu \mathrm{m}$ effective radius for the ice cloud parameterisation used.

\subsection{Surface}

The underlying surface is described in terms of a Lambertian spectral albedo taken from the MODIS albedo product MOD43C1 (Schaaf et al., 2002) for the year 2004 and the Julian day 225 for the area corresponding to the COSMO-EU region and the 7 solar MODIS channels contained in the spectral range $460 \mathrm{~nm}-2155 \mathrm{~nm}$ for which albedo has been derived. From MODIS thermal channels emissivity is derived by the MODIS land surface team and made publicly available in form of the MOD11C2 product (Wan and $\mathrm{Li}$, 1997). For the year 2004 and the Julian day 225 emissivities for wavelengths around 3.9, 8.7, 10.8 and $12.0 \mu \mathrm{m}$ have been extracted from the appropriate product, transformed into albedos (emissivity $=1-$ albedo) and gathered into spectral albedo files for every resolution enhanced COSMO-EU pixel.

Albedo values are interpolated linearly between MODIS channels and assumed constant below $460 \mathrm{~nm}$ and above $12.3 \mu \mathrm{m}$. For water bodies, surface albedo was computed in clear sky conditions for all MET-8/SEVIRI solar channels by using the ocean BRDF by Nakajima and Tanaka (1983) and Cox and Munk (1954a,b). These values were then again collected into a spectral albedo file and used as input to the radiative transfer simulations.

Examples of the resulting albedos and emissivities are given in Fig. 4.

\subsection{Solar and viewing geometry}

Solar zenith angles, satellite zenith angles and relative azimuth angles between sun and satellite have been produced for the geographic location of every COSMO-EU pixel in higher resolution, i.e. after downscaling. Sun zenith angle lies in the range $25.1^{\circ}-48.5^{\circ}$ (mean value $\left.=36.5^{\circ}\right)$, satellite zenith angle in the range $45.1^{\circ}-72.0^{\circ}$ (mean value $\left.=58.6^{\circ}\right)$, relative azimuth angle in the range $0.0^{\circ}-12.2^{\circ}$ (mean value $=4.5^{\circ}$ ). The satellite selected is MET-8 (MSG-1) located at $-3.4^{\circ} \mathrm{E}$, which was its operational orbit position until April 2008. 

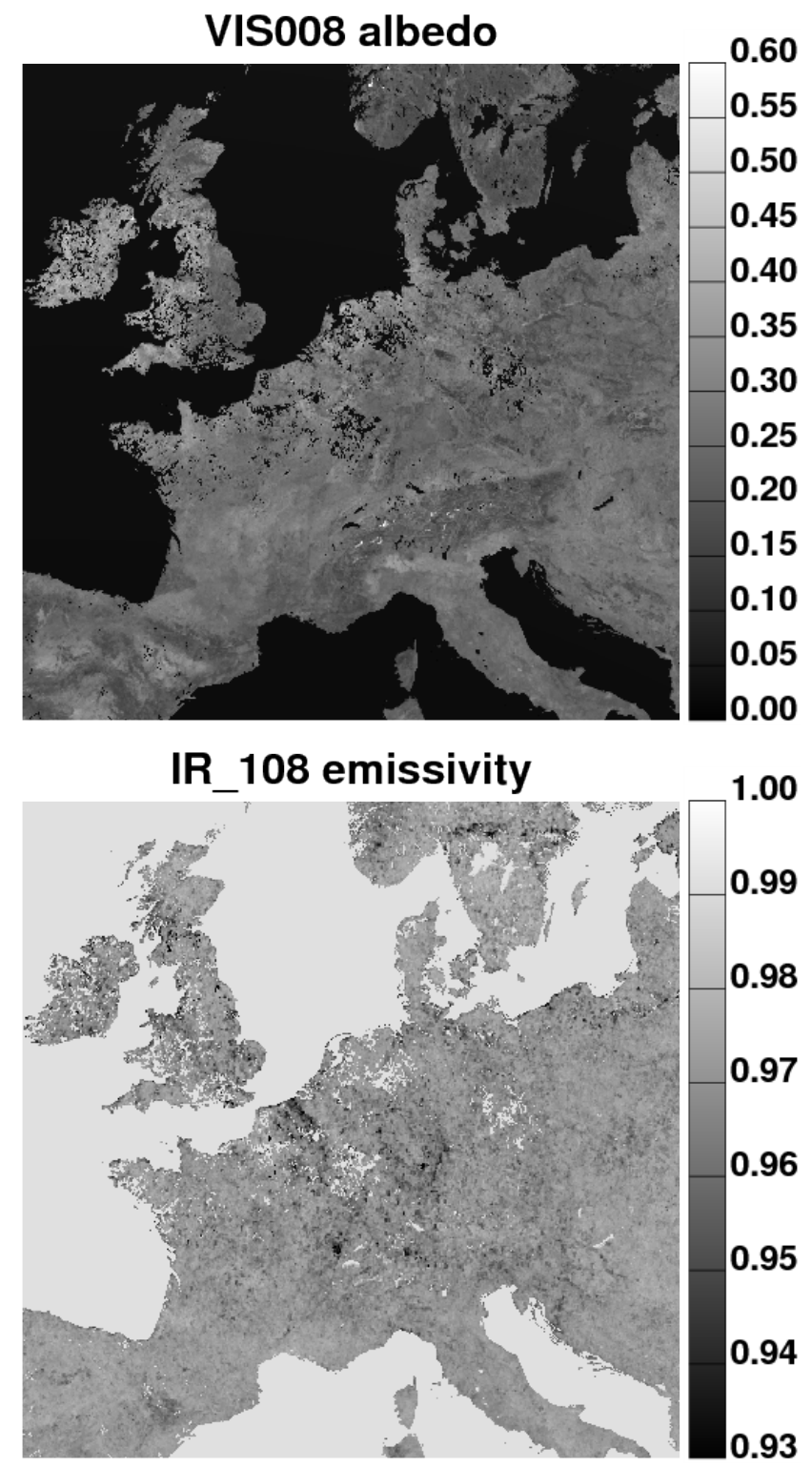

Fig. 4. Example of (top) SEVIRI albedo for channel VIS008 and (bottom) SEVIRI emissivity for channel IR_108. Both quantities have been extracted from MODIS products and are displayed on the resolution enhanced COSMO-EU grid.

\section{Simulations}

Starting from the data sets and the radiative transfer model described in Sect. 3 radiances for every MET-8/SEVIRI channel have been computed. Two examples, the solar channel VIS008 and the thermal water vapour channel WV_062, are shown in Fig. 5.

To take into account the misleading definition of spectral radiance in the thermal range (eum, 2007) used by EUMETSAT's Meteorological Product Extraction Facility for the processing of the Meteosat Second Generation data, an algorithm has been written that transforms the correct spectral radiances (also called effective spectral radiances in the mentioned EUMETSAT document) produced by the radiative transfer model into spectral radiances (i.e. at a defined wavenumber) as they are expected by most algorithms for the detection of clouds that have been tuned and tested with real data so far.

After this correction radiances are convolved with the instrument point spread function and brought into MET-8/SEVIRI projection by averaging all model values that belong to a given satellite pixel.

The resulting MET-8/SEVIRI area simulated in this study thus comprises elements 1335 to 2111 and lines 3132 to 3536 in native coordinates (i.e. from the South-Eastern corner of the MET- 8 disc where the SEVIRI spinning radiometer starts scanning the Earth).

Based on these simulated channels a false colour composite has been produced and is plotted in Fig. 6 together with a false colour composite for the same time but from real MET- 8 data. This way, the forecast of the COSMO-EU model can be directly evaluated. It shows that apart from a phase shift the cloud front is well described. However, it is also apparent that the model predicts too many cirrus clouds and to few middle level clouds.

Plots of all channels are given in Appendix A, Figs. A1 and A2.

\section{Cloud property retrievals}

For this case study the APICS (Algorithm for the Physical Investigation of Clouds with SEVIRI) developed at DLR and the operational CMSAF software developed at the French national meteorological service METEO FRANCE and the Royal Netherlands Meteorological Institute KNMI have been selected to show the potential of this method to quantitatively validate cloud property retrievals. However, the focus does not lie on the validation of these particular retrieval algorithms but on the advantages and opportunities of the validation method. For this reason, the single algorithms are only sketched in the following Sects. 5.1 and 5.2.

\subsection{APICS}

\subsubsection{Cloud detection}

The APICS cloud masking algorithm has inherited its structure from the EUMETSAT scenes detection algorithm (Lutz, 1999, 2002; Lutz et al., 2003). It is based on six groups of threshold tests applied to several SEVIRI channels. In particular, a cloud is detected if one of the tests gives a positive result. The first five groups represent standard tests (similar to Saunders and Kriebel, 1988; Kriebel et al., 2003) and comprise reflectance tests, reflectance ratio tests, temperature tests, temperature difference tests, and spatial coherence tests. The last test group aims at cirrus clouds alone: a cirrus cloud is detected when at least one of the cirrus tests described in Krebs et al. (2007) gives a positive result. This day and night cirrus algorithm consists of six sub-tests based on the infrared SEVIRI channels alone that exploit spectral as well as morphological properties of cirrus clouds.

Threshold values used in the tests are either determined empirically, or derived from clear-sky albedo maps applying an atmospheric and viewing angle correction, or they are obtained from NWP (ECMWF) data by means of the libRadtran radiative transfer model (see also following Sect. 5.1.2). 


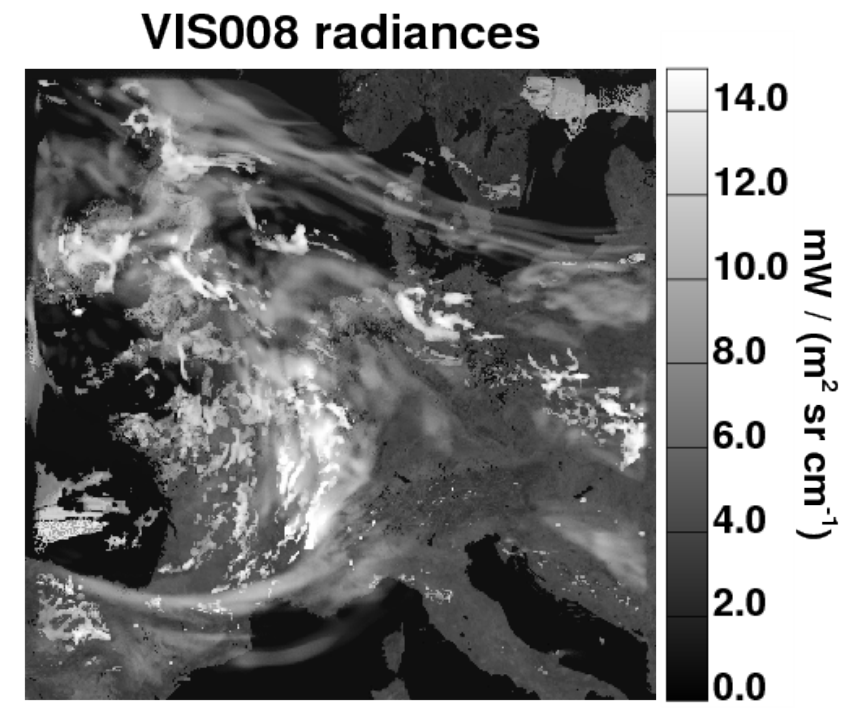

WV_062 radiances

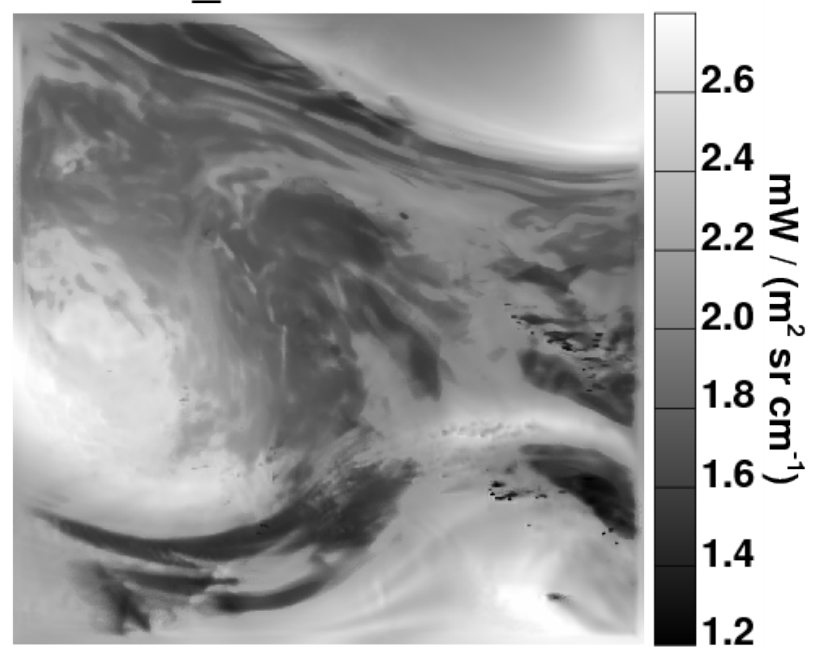

Fig. 5. Example of SEVIRI radiances computed with libRadtran: (top) solar channel VIS008 centred at $0.8 \mu \mathrm{m}$ and (bottom) water vapour channel WV_062 centred at $6.2 \mu \mathrm{m}$. Both plots are on the MODEL grid.

\subsubsection{Cloud top height}

In order to infer cloud top height (i.e. pressure and temperature) two techniques are used: for opaque clouds, the measured IR_108 window channel brightness temperature is matched against a collocated atmospheric temperature profile obtained from ECMWF analysis data. In the case of semi-transparent or sub-pixel clouds, however, this technique fails and the $\mathrm{CO}_{2}$ slicing method is used. Here, infrared channel radiances at IR_108 and at IR_134 for black clouds located at different layers of the atmosphere are ratioed (Cayla and Tomassini, 1978; Szejwach, 1982; Nieman et al., 1993; Menzel et al., 1983; Schmetz et al., 1993). For both methods atmospheric profiles of temperature, pressure, water vapour and ozone are taken from ECMWF analyses with a $0.25^{\circ} \times 0.25^{\circ}$ spatial resolution in longitude and latitude. These are input to libRadtran to simulate
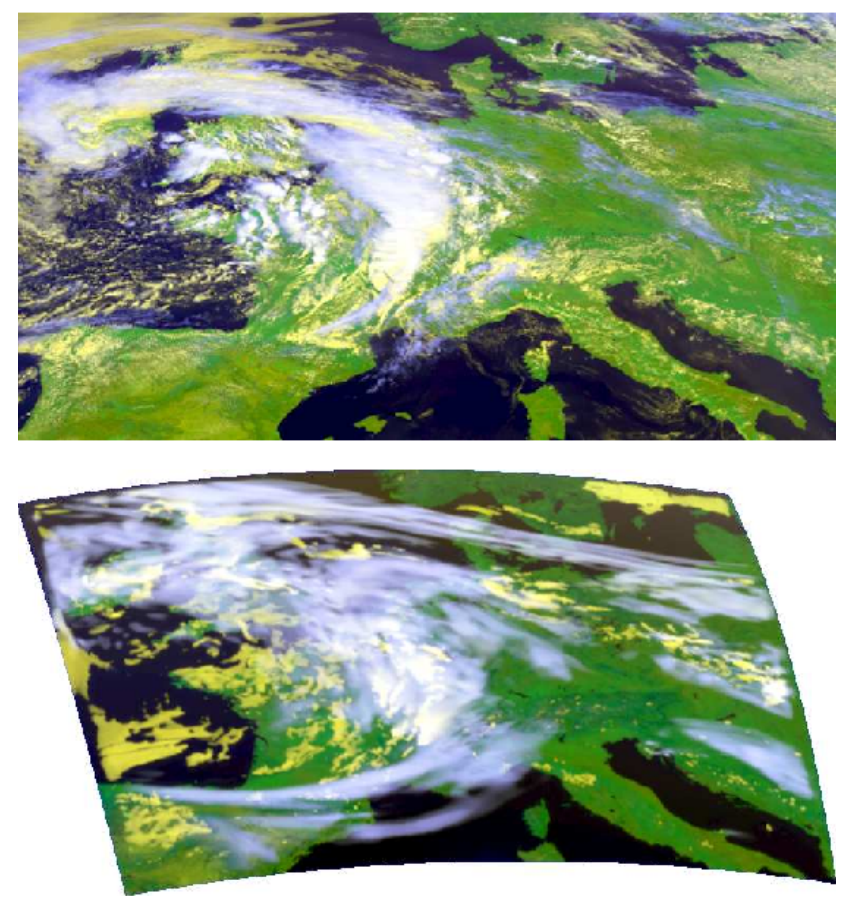

Fig. 6. (Top) false colour composites of a real MET-8/SEVIRI observation from 12 August 2004, 12:00 UTC; (bottom) simulated satellite observation, for the same date and time and processed by the same false colour algorithm.

top-of-atmosphere radiances from black clouds located at different levels in the atmosphere. The vertical grid chosen here sets black cloud tops from the surface to $15 \mathrm{~km}$ altitude in $1 \mathrm{~km}$ steps.

\subsubsection{Cloud top phase}

Ice clouds are assumed when the cirrus detection results by Krebs et al. (2007) are positive. All other clouds are classified as liquid water clouds.

\subsubsection{Cloud optical thickness and effective radius}

Two channels are used for the determination of cloud optical thickness and cloud effective radius: VIS006 (without water or ice absorption) and IR_016 (with water or ice absorption). The algorithm is based on the method described by Nakajima and King (1990) and Nakajima and Nakajima (1995), but has been adapted to MET8/SEVIRI in order to make use of the two solar channels instead of the three classical channels centred around 0.6, 3.7 and $11 \mu \mathrm{m}$. Comparison of pre-calculated values of the reflectivities with corresponding measured quantities yields the optical thickness and effective radius that best reproduce the measurements. For this purpose, reflectivities calculated by libRadtran are tabulated in advance as a function of the relevant parameters (sun zenith angle, sensor zenith angle, relative azimuth angle, surface albedo, cloud optical thickness, and effective particle radius). Water cloud effective radii run from 5 to $25 \mu \mathrm{m}$ while ice cloud effective radii are in the range 6-84 $\mu \mathrm{m}$. Water cloud optical properties are computed according to Mie theory, while ice cloud optical properties are parameterised 
after Key et al. (2002); Yang et al. (2000). In particular, $r_{\text {eff }}$ for ice particles equals $\frac{3}{4} V / A$, where $V$ is the total volume of the particles and $A$ is the total projected area. It has to be noticed that the treatement of ice particles (and of water droplets as well) is entirely consistent with the simulations described in Sect. 3.2. Information about surface albedo over land is extracted from the MODIS white sky albedo product $\mathrm{MCD} 43 \mathrm{C} 3$ with a $0.05^{\circ}$ spatial resolution for MODIS bands $1(620-670 \mathrm{~nm})$ and $6(1628-1652 \mathrm{~nm})$.

\subsubsection{Cloud water path}

For this study APICS has been extended by adding cloud water path CWP to the list of output variables. This quantity is derived from retrieved cloud optical thickness $\tau$ and droplet effective radius $r_{\text {eff }}$ (see Sect. 5.1.4) by means of the relation (Stephens, 1978):

$\mathrm{CWP}=\frac{2}{3} \tau r_{\mathrm{eff}} \rho$,

where $\rho$ is the density of water. In the case of liquid water clouds (see Sect. 5.1.3), the density of liquid water $1000 \mathrm{~kg} / \mathrm{m}^{3}$ is used, for ice clouds, the density of ice $917 \mathrm{~kg} / \mathrm{m}^{3}$.

\subsection{CMSAF}

As a second test retrieval we selected the operational software used by the Climate Monitoring Science Application Facility (CMSAF) for the creation of long term data sets of cloud properties. It consists of two parts: the first one includes the SAFNWC/MSG version 1.4 (2008) software developed by METEO FRANCE (Derrien and LeGleau, 2005; SAFNWC, 2007) in the framework of the Science Application Facility for Nowcasting (SAFNWC): in this study we used the products PGE01 (cloud mask) and PGE03 (cloud top temperature). The second part consists in the cloud physical product retrieval CPP from Roebeling et al. (2006) and Meirink et al. (2010) that derives cloud optical thickness and cloud water path.

\subsubsection{Cloud detection}

The algorithm is based on multispectral threshold techniques applied to each pixel and works in four steps. In the first step, a series of tests allows the identification of pixels contaminated by clouds or snow/ice. Similarly to APICS, reflectance tests, temperature tests, temperature difference tests, and spatial coherence tests are applied. Most thresholds are determined from sun- and satellite-dependent look-up tables and make use of NWP forecast fields (surface temperature and total atmospheric water vapour content) and ancillary data (elevation and climatological data) from the GME model (Majewski, 1998; Majewski et al., 2002) with a resolution of $0.5^{\circ} \times 0.5^{\circ}$ in latitude and longitude. These thresholds are computed at a spatial resolution of $16 \times 16$ pixels. The second step consists of two tasks: on one hand, a consistency check is performed where pixels having a class type different from their neighbours are reclassified. On the other hand, an opacity and a complete overcast cloud flag is extracted for all cloud contaminated pixels. The third step consists in the assessment of the quality of the cloud detection process, while the last step identifies dust clouds and volcanic ash clouds and is applied to all pixels. More details can be found in (SAFNWC, 2007).

\subsubsection{Cloud top height}

The basis for cloud top height retrievals are simulated vertical profiles of cloud free and overcast radiances and brightness temperatures for the thermal SEVIRI channels WV_062, WV_073, IR_134, IR_108 and IR_120. They are computed with the RTTOV-7 radiative transfer model (Saunders et al., 2002) applied to NWP temperature and humidity vertical profiles with a horizontal spatial resolution of $32 \times 32$ SEVIRI pixels. For opaque clouds, the cloud top pressure corresponds to the best fit between the simulated and the measured IR_108 brightness temperatures. In the case of semi-transparent or sub-pixel clouds two bi-spectral techniques are used instead: first, the $\mathrm{H}_{2} \mathrm{O}$ intercept method is applied sequentially to a window (IR_108) and a sounding (IR_134, WV_073, WV_062) channel. In its original formulation, it exploits the fact that water vapour radiances vary linearly against IR window radiances as a function of cloud amount to extrapolate the correct cloud height (see references in Sect. 5.1.2). The final retrieved cloud top pressure is the averaged cloud top pressure obtained using single sounding channels. If this first step fails, the radiance ratioing method, adapted from the $\mathrm{CO}_{2}$ slicing by (Smith et al., 1970; Chahine, 1974; Smith et al., 1974; Smith and Platt, 1978; Menzel et al., 1983; Eyre and Menzel, 1989; Nieman et al., 1993), is applied successively to the window IR_108 and the sounding channels WV_073, WV_062 and IR_134 until a result is obtained. In case this result is warmer than the corresponding IR_108 brightness temperature, the method for opaque clouds is used instead.

\subsubsection{Cloud top phase, cloud optical thickness and cloud effective radius}

The method iteratively interprets reflected solar radiation in the VIS006 and IR_016 channels in terms of cloud top phase, cloud optical thickness and cloud effective radius. The physical basis for the determination of optical thickness and effective radius is the same as in Nakajima and King (1990) and Nakajima and Nakajima (1995): they are obtained by simultaneously comparing satellite observed reflectances at visible and near-infrared wavelengths to look-up tables of simulated reflectances. In addition the method exploits the fact that at $1.6 \mu \mathrm{m}$ the imaginary index of refraction is higher for ice particles than for liquid particles to infer cloud phase (see for instance Baum et al. (2000)).

The algorithm, described in Roebeling et al. (2006), starts with retrieving a cloud optical thickness at $0.6 \mu \mathrm{m}$ that is used to update the retrieval of particle size at $1.6 \mu \mathrm{m}$. This iteration process initially assumes ice clouds and continues until the retrieved cloud physical properties converge to stable values. In this case, infrared cloud emissivity is computed from the optical thickness according to (Minnis et al., 1993), and this quantitity is used to correct the $10.8 \mu \mathrm{m}$ brightness temperature and obtain cloud top temperature. If this is lower than $265 \mathrm{~K}$, ice phase is maintained, otherwise the iteration scheme is started from scratch again assuming liquid water clouds. Finally, for optically thin clouds (optical thickness $<8$ ) the retrieved particle sizes are reset to climatological values of $8 \mu \mathrm{m}$ for water and $26 \mu \mathrm{m}$ for ice clouds, values close to those used by Rossow and Schiffer (1999). To obtain a smooth transition between assumed and retrieved effective radii a weighting function is applied to the effective radii of cloudy pixels with optical thickness between zero and eight. 
The Doubling-Adding KNMI (DAK) monochromatic radiative transfer model (de Haan et al., 1987; Stammes, 2001) is used to compile the required look-up tables. To translate line reflectances into SEVIRI channel reflectances, line-to-band conversion coefficients are computed by convolving Scanning Imaging Absorption Spectrometer for Atmospheric Chartography (SCIAMACHY, aboard the european research satellite ENVISAT, Stammes et al., 2005) spectra with the SEVIRI spectral response functions (Roebeling et al., 2006). For water clouds optical properties are obtained from Mie theory for effective radii (Hansen and Travis, 1974) between 1 and $24 \mu \mathrm{m}$; for ice clouds a homogeneous distribution of $\mathrm{Cb}, \mathrm{C} 1, \mathrm{C} 2$ and $\mathrm{C} 3$ type imperfect hexagonal ice crystals from Hess et al. (1998) is used with volumetric radii $r_{v}$ of $6,12,26$ and $51 \mu \mathrm{m}$ respectively (see Sect. 3.1.3 for the definition of this radii).

Cloud top phase corresponds to the resulting phase used in the $\tau-r_{\text {eff }}$ retrieval (Wolters et al., 2008).

Unlike in the operational chain at CMSAF, the algorithm is run here without re-calibrating the solar channels to take into account the fact that simulated radiances are exact.

Over land the underlying surface albedo is the average of three years of MODIS whitesky albedo data for the corresponding MODIS 0.6 and $1.6 \mu \mathrm{m}$ channels. Over sea the surface albedo is assumed to be 0.05 at both $0.6 \mathrm{~m}$ and $1.6 \mu \mathrm{m}$.

\subsubsection{Cloud water path}

Cloud water path CWP is derived from retrieved cloud optical thickness $\tau$ and droplet effective radius $r_{\text {eff }}$ (see Sect. 5.2.3) by means of Eq. (2). Equality holds true when the size parameter $2 \pi r / \lambda$ is large enough such that scattering efficiency can be approximated with a value of 2. This is only completely correct for water clouds and under the assumption that the cloud has a constant effective radius vertical profile. The CPP algorithms first computes optical thickness $\tau$ and effective radius $r_{\text {eff }}$ and then derives cloud water path according to the above equation. Since in the CMSAF processing chain only optical thickness and cloud water path are output, we do not present a validation for effective radius here.

\section{Validation}

We show a paradigmatic validation of the two spaceborne cloud retrievals APICS and CMSAF for MET-8/SEVIRI (Sect. 5) by means of the simulated satellite scene presented in Sect. 4. The application of the schemes on simulated data instead of real data enables an objective validation of the algorithms since all the components of the Earth-atmosphere system that lead to the "observed" satellite radiances are known and can be directly compared to the output fields of the retrieval algorithms.

In the following we will denote by "retrieved" all the cloud properties that are output of the satellite retrievals. In contrast, the word "real" or "reality" will be used to characterise those cloud properties that stem from the COSMO-EU weather model, have been subsequently downscaled and finally used as input to the radiative transfer model for the simulation of the satellite scene. In fact, these are the cloud properties that lead to the radiance fields used in this study.

To make a comparison of retrieved and real cloud properties possible, real cloud properties have been projected to the MET8/SEVIRI grid in a similar way as the simulated radiances (see
Sect. 4). More details will be given in the next subsections when cloud mask (Sect. 6.1), cloud top temperature (Sect. 6.3), cloud top phase (Sect. 6.2), cloud optical thickness (Sect. 6.4), cloud water path (Sect. 6.6) and cloud effective particle radius (Sect. 6.5) will be addressed. However, Table 2 summarises all relevant real cloud properties of concern.

\subsection{Cloud detection}

Reality is represented in this case by the projection of the real binary $(0 / 1)$ cloud mask originally defined on the downscaled COSMOEU grid onto the MET-8/SEVIRI grid. This first yields a cloud cover mask from which a cloud mask has been obtained: all MET8/SEVIRI pixels with cloud cover larger than zero have been defined to be cloudy.

The APICS retrieval yields directly a binary cloud mask, while more than one CMSAF output field has been combined into a cloud mask. First, the PGE01 product flags for "cloud contaminated" and "cloud filled" pixels were used to identify cloudy pixels. Second, the corresponding CMSAF dust and volcanic ash detection products were considered in order to cleanse the cloud mask from these spurious contaminations (which in this case were almost nonexistent). Finally, the CMSAF cloud mask quality flag was used to select only high confidence pixels. This provides us with two retrieved cloud masks (APICS and CMSAF) that can be validated against the real cloud mask.

The discrepancies between APICS and real cloud mask as well as between CMSAF and real cloud mask are plotted in Fig. 7a and b. It can be seen that the two retrieved cloud masks are similar to each other. In fact, both cloud detection schemes show their capability to reproduce the input cloud distribution. Nevertheless, a pure comparison of the retrievals' output, without knowledge about the real cloud distribution in the observed domain, could lead to erroneous conclusions. For instance, one can see in the South-Western part of the picture that neither scheme is able to detect the edges of the cloud field (the coincident red colour in the cloud mask difference plots). On the contrary, some pixels are retrieved as overcast by both retrievals while in reality they are not (the turquoise colour).

In order to quantitatively assess the performance of the cloud detection algorithms, we evaluate various statistics including the Hanssen-Kuiper (HK) skill score (Hanssen and Kuipers, 1965), also called true skill score, applied to the pixels of the simulated scene. This measure is often used to evaluate the skill of precipitation forecasts (see Tartaglione (2010) and references therein) but also of cloud detection schemes (Reuter et al., 2009). The HK skill score is based on the $2 \times 2$ contingency table of the detection events (Table 3). The four elements of the table are the hit $a$, false alarm $b$, miss $\mathrm{c}$, and correct negative events d. The HK score, defined as

$\mathrm{HK}=\frac{a d-b c}{(a+b)(c+d)}=\frac{d}{c+d}+\frac{a}{a+b}-1$,

is independent of the distribution of events (really cloudy pixels) and nonevents (really cloud free pixels) (Woodcock, 1976), and can be expressed as the sum of the accuracy for events (probability of cloud detection, first term in Eq. (3)) and the accuracy of nonevents (probability of cloud free detection, second term in Eq. (3)) plus -1 to ensure that $-1 \leq \mathrm{HK} \leq 1$. An $\mathrm{HK}$ score equal to 1 is associated with a perfect cloud detection $(b=c=0)$, while a score of -1 means that hits and correct negatives are zero $(a=d=0)$. The 

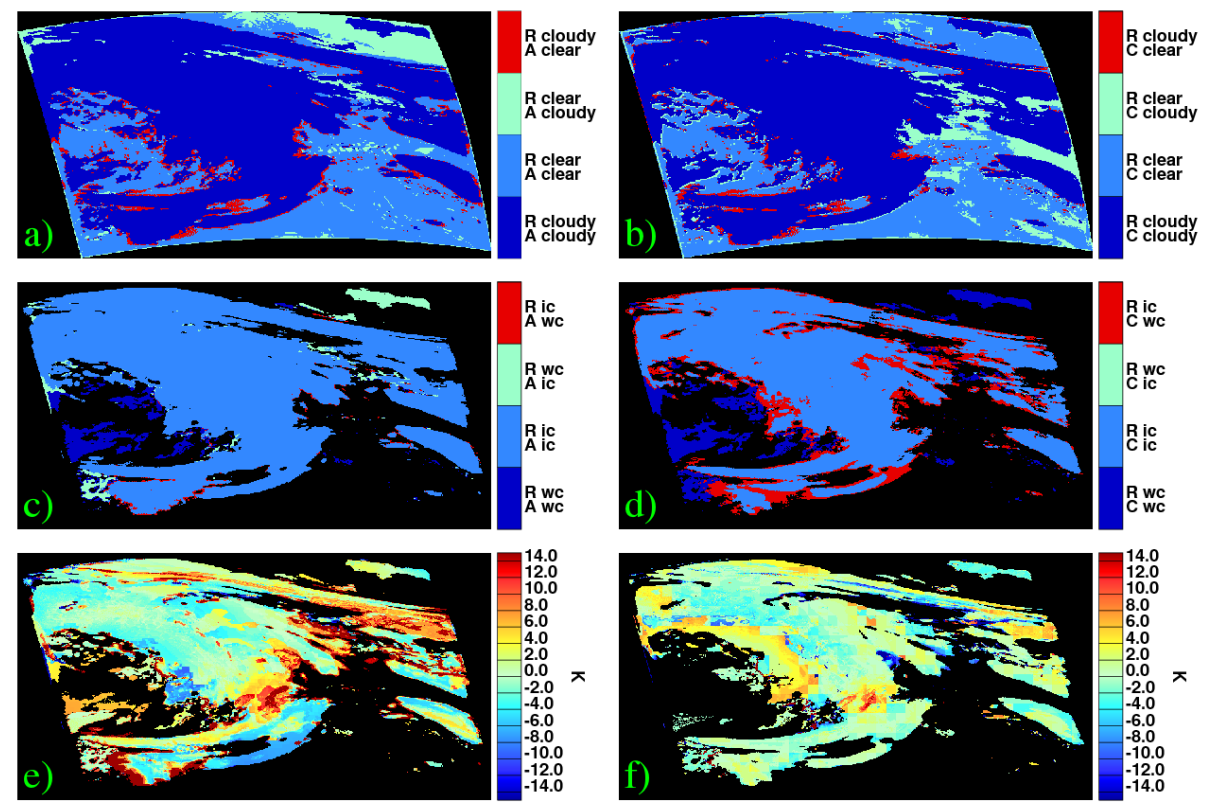

Fig. 7. Differences between retrieval results and real cloud properties. (a) Differences between real and APICS cloud mask. "R clear/cloudy" means that the pixel is really clear/cloudy, "A clear/cloudy" means that the pixel is cloudy/clear according to the APICS retrieval. (b) Differences between real and CMSAF cloud mask. "R clear/cloudy" means that the pixel is really clear/cloudy, "C clear/cloudy" means that the pixel is cloudy/clear according to the CMSAF retrieval. (c) Differences between real and APICS cloud top phase. "R wc/ic" means that the pixel contains a real water/ice cloud, "A wc/ic" means that the pixel contains a water/ice cloud according to APICS. (d) Differences between real and CMSAF cloud top phase. "R wc/ic" means that the pixel contains a real water/ice cloud, "C wc/ic" means that the pixel contains a water/ice cloud according to CMSAF. (e) Differences between retrieved and real cloud top temperatures for APICS. (f) Differences between retrieved and real cloud top temperatures for CMSAF.

HK score is equal to 0 for a constant forecast (either $a=c=0$ or $b=d=0)$.

Considering first APICS (Fig. 7a), four features are observable: (1) an extended cloud field is detected in the North-Eastern corner of the simulation which is actually much smaller; (2) some coastlines are classified as clouds; (3) many of the cloud border pixels, with fractional cloud cover, are not detected; (4) some mistakenly detected cloud over the Alps. In more detail, the domain considered contains 254184 pixels, 156135 are cloudy and the remaining 98049 are clear. The retrieval output and the real cloud mask both contain a cloud in 144830 pixels, i.e. $93 \%$ of all cloudy pixels have been detected. Only $\approx 7 \%$ of the cloudy pixels have not been detected (11305 pixels), while the false alarm rate (clear pixels that are retrieved as cloudy) amounts to $8 \%$, i.e. 19105 . Unfortunately, due to the features identified above, only approximately $81 \%$ of the input clear pixels are classified accordingly by APICS. Altogether, the retrieval agrees with the reality, both clear or both cloudy, on approximately $88 \%$ of all pixels (223 774 pixels). The HK score is 0.73 .

Considering CMSAF, (Fig. 7b), as for APICS, some of the cloud border pixels with fractional cloud cover are not classified correctly, while in the Eastern part of the simulation some nonexistent cloud is detected. CMSAF detects $95 \%$ (147 771 pixels) of all cloudy pixels, the false alarm rate amounts to $8.7 \%$ (22 175 pixels have been mistakenly classified as cloudy). Altogether, only approximately $77 \%$ of the really clear pixels are classified as that by CMSAF (75 874 pixels). Retrieval and reality agree (both clear or both cloudy) on
$88 \%$ of all pixels (223 645 pixels). The corresponding HK score is 0.77 .

\subsection{Cloud top phase}

The real cloud top thermodynamic phase on the SEVIRI grid is computed from the original quantity on the downscaled COSMOEU grid by "averaging" the cloud top values for all pixels belonging to the same satellite pixel. Since both water and ice clouds could be present inside a MET-8/SEVIRI pixel after re-projection, we decided to label the pixel according to the cloud top phase that appears most frequently in that pixel.

Since retrieved and real cloud mask differ, the validation of all retrieved cloud products over every single retrieval algorithm is restricted to the pixels that are cloudy in the real as well as in the retrieved cloud mask. This new cloud mask is called common cloud mask. Since two retrieval algorithms are investigated there are two common cloud masks, one for APICS and one for CMSAF.

The common cloud mask for APICS contains 144830 cloudy pixels. Out of them, 14516 are real water and 130314 real ice clouds. The APICS retrieval classifies 59\% (8630 pixels) of the real water clouds as water and $99 \%$ (128672 pixels) of the real ice clouds as ice. The lower accuracy for water clouds (see Fig. 7a and c) is produced by the wrong classification of the cloud field in the North-Eastern corner. Here, APICS erroneously detects an extended cirrus (ice) cloud. Since a subset of these pixels contains a real water cloud, we obtain as a result a wrong cloud top phase for these pixels. Because this cloud makes up more or less half of 
Table 2. Summary of real cloud properties after projection to the MET-8/SEVIRI grid. CTP = Cloud Top Phase, WC $=$ Water Cloud, IC $=$ Ice Cloud, $\mathrm{CC}=$ Cloud Cover, CTT $=$ Cloud Top Temperature, CWP $=$ Cloud Water Path, $\tau=$ Optical Thickness, $r_{\text {eff }}=$ Effective Radius, $\sigma_{\tau}=$ Standard Deviation of Optical Thickness inside every single pixel.

\begin{tabular}{|c|c|c|c|}
\hline & Cloudy & Clear & Total \\
\hline \multirow[t]{3}{*}{ \# pixels } & 156135 & 98049 & 254184 \\
\hline & Water & Ice & Multi-phase \\
\hline & Clouds & Clouds & Clouds \\
\hline \# pixels & 17352 & 109857 & 28926 \\
\hline with $\mathrm{CTP}=\mathrm{WC}$ & 17352 & 0 & 600 \\
\hline with CTP = IC & 0 & 109857 & 28326 \\
\hline with $\mathrm{CC}=1$ & 13504 & 100644 & 28452 \\
\hline with $0<\mathrm{CC}<1$ & 3848 & 9213 & 474 \\
\hline \multirow{2}{*}{ Property } & Water & Ice & Multi-phase \\
\hline & Clouds & Clouds & Clouds \\
\hline Min CTT/K & 268.0 & 210.0 & 210.0 \\
\hline Max CTT/K & 294.0 & 272.0 & 279.0 \\
\hline Mean CTT/K & 282.6 & 222.6 & 226.4 \\
\hline Std CTT/K & 3.6 & 6.4 & 8.8 \\
\hline Min CWP/g m ${ }^{-2}$ & $4.31 \mathrm{e}-4$ & $2.75 \mathrm{e}-4$ & 0.107 \\
\hline $\mathrm{Max}$ CWP/g m ${ }^{-2}$ & 904.40 & 2239.7 & 6241.8 \\
\hline Mean CWP/g m ${ }^{-2}$ & 35.37 & 69.19 & 187.42 \\
\hline Std CWP/g m ${ }^{-2}$ & 37.44 & 112.82 & 323.20 \\
\hline $\operatorname{Min} \tau$ & $8.10 \mathrm{e}-4$ & $5.47 \mathrm{e}-6$ & $9.94 \mathrm{e}-3$ \\
\hline $\operatorname{Max} \tau$ & 150.0 & 46.00 & 224.85 \\
\hline Mean $\tau$ & 9.13 & 2.15 & 17.42 \\
\hline $\operatorname{Std} \tau$ & 7.45 & 2.71 & 22.46 \\
\hline $\operatorname{Min} r_{\mathrm{eff}} / \mu \mathrm{m}$ & 1.0 & 11.63 & 1.78 \\
\hline $\operatorname{Max} r_{\mathrm{eff}} / \mu \mathrm{m}$ & 10.43 & 84.22 & 82.74 \\
\hline Mean $r_{\text {eff }} / \mu \mathrm{m}$ & 5.32 & 41.32 & 24.56 \\
\hline $\operatorname{Min} \sigma_{\tau}$ & $4.32 \mathrm{e}-4$ & $9.06 \mathrm{e}-6$ & $9.99 \mathrm{e}-05$ \\
\hline $\operatorname{Max} \sigma_{\tau}$ & 43.54 & 7.07 & 72.05 \\
\hline Mean $\sigma_{\tau}$ & 1.51 & 0.14 & 2.88 \\
\hline $\operatorname{Std} \sigma_{\tau}$ & 1.84 & 0.16 & 4.06 \\
\hline
\end{tabular}

all real water clouds, the retrieval performance is heavily affected. Overall, reality and APICS agree for almost 95\% (137302 pixels) of all common cloud pixels.

The common cloud mask for CMSAF is composed of 147771 cloudy pixels. For $6.3 \%$ (9316 pixels) of these clouds, no cloud phase could be assigned. Out of the remaining 138455 pixels, 15812 are real water and 122643 real ice clouds. The CMSAF retrieval classifies almost 100\% (15764 pixels) of the real water clouds as water and $82 \%$ (100396 pixels) of the real ice clouds as ice. The large difference for ice clouds (see Fig. $7 b$ and d) is produced by the erroneous classification of the cloud edges. Overall, reality and CMSAF algorithm agree for $84 \%$ (116 160 pixels) of all common cloud pixels.
Table 3. Contingency table applied to every pixel of the simulated scene.

\begin{tabular}{llccl}
\hline & & \multicolumn{2}{c}{ Retrieval } & \\
\cline { 3 - 4 } & Scenario & Cloud free & Cloudy & Total \\
\hline Reality & Cloud free & $a$ & $b$ & $a+b$ \\
& Cloudy & $c$ & $d$ & $c+d$ \\
\hline & Total & $a+c$ & $b+d$ & $N=a+b+c+d$ \\
\hline
\end{tabular}

\subsection{Cloud top temperature}

Cloud top temperature has a direct impact on the outgoing longwave radiation at top-of-atmosphere since it determines cloud emission. Furthermore, temperatures are directly measured by the SEVIRI sensors in its thermal channels and through this quantity height assignment is performed. Thus, the two related quantities, cloud top height and cloud top pressure, are neglected and the focus is put on cloud top temperatures. Again, the comparison between reality and retrievals is made on the basis of the common cloud masks (144830 and 147771 pixels for APICS and CMSAF respectively), regardless of the fact that some cloud pixels have been assigned the wrong thermodynamic phase since this information does not enter the computation of cloud top temperatures. CMSAF however produces reliable cloud top temperatures for a subset of 124255 pixels, i.e. to $16 \%$ of the cloudy pixels was assigned the default value of $150 \mathrm{~K}$. Only the non-default CMSAF pixels are investigated in the following. Figure $7 \mathrm{e}$ and $\mathrm{f}$ show relative differences between retrieved and real cloud top temperatures for APICS and CMSAF respectively. Largest discrepancies are produced by APICS at the edges of cirrus clouds, but the overall agreement is good. The APICS mean difference is $3.1 \mathrm{~K}$ with a standard deviation of $10.6 \mathrm{~K}$ (the mean cloud top temperature of the real clouds investigated here is $228.8 \mathrm{~K}$ ). This slight overestimation of cloud top temperature means that cloud tops are located lower in the atmosphere by the APICS retrieval than they are in reality. This is a usual feature of the technique employed (see Sect. 5.1.2) since it determines the height (temperature) of the "radiative centre" of the cloud (Menzel et al., 1992), which is located lower in the atmosphere.

Figure $7 \mathrm{f}$ shows relative differences between CMSAF and real cloud top temperatures. The box structures that can be observed stem from the coarser resolution of the NWP model used for the preparation of the ancillary data set of black cloud radiances (see Sect. 5.2.3). Largest discrepancies (underestimations) are produced here at the edges of cirrus clouds but also some water cloud temperature is underestimated. The overall agreement is good. The mean CMSAF difference is $0.12 \mathrm{~K}$ with a standard deviation of $7.6 \mathrm{~K}$ (the mean cloud top temperature of the real clouds investigated here is $226.8 \mathrm{~K}$ ). The pixels that could not be evaluated correspond prevalently to (thin ice) cloud edges.

Finally, considering the distribution of retrieved and real cloud top temperatures as in Fig. 8 we note that the first peak of real values (green line) located between 215 and $220 \mathrm{~K}$ (ice clouds) is slightly shifted to higher values, especially for APICS (225-230 K). The second, smaller peak at 285-290 K (water clouds) is less pronounced and smoother in both retrieval results. In the range between these two peaks APICS is assigning more clouds while CMSAF less 


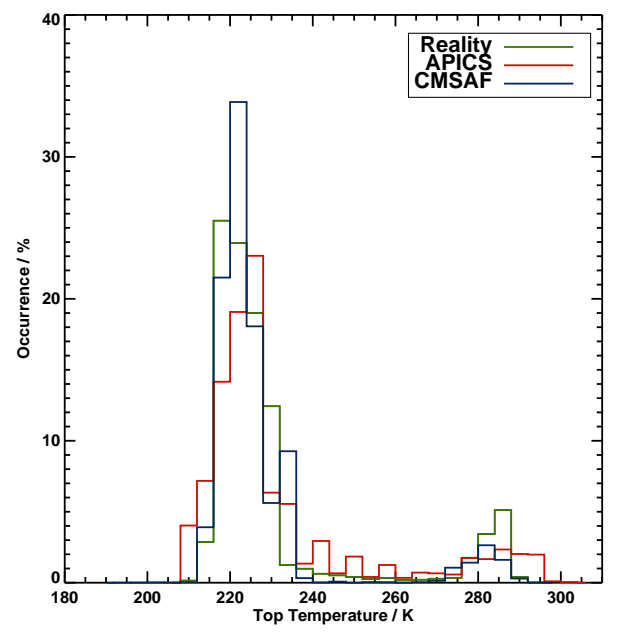

Fig. 8. Histograms of real, APICS and CMSAF cloud top temperatures.

clouds than are really present. APICS also shows here an interpolation artefact.

\subsection{Cloud optical thickness}

We restrict the validation to those pixels that belong to the common cloud masks, like in the previous sections (Sects. 6.2 and 6.3). Furthermore, we only consider a subset of this common cloud mask where both retrieved and real clouds have the same top thermodynamic phase and exclude those pixels that show an unusually low albedo value (recognisable in the top panel of Fig. 4 as dark spots). Finally, we distinguish between those cloudy pixels that exclusively contain either water or ice clouds, and those that contain water and ice clouds at the same time. In this last pixel class, called multi-phase, the following various cloud situations are collected: vertically extended clouds like cumulonimbus that are made up of liquid water droplets at their base and of ice crystals at their top, pixels where a water cloud and a contiguous cirrus cloud coexist and clouds containing mixed phase layers with both liquid water droplets and ice particles or cirrus clouds on top of liquid water clouds. These kinds of clouds are distinguished since they do not correspond to any of the cloud classes considered (pure water or pure ice) in the retrievals and therefore larger inaccuracies are expected in cloud optical thickness and effective radius. The distribution of real water, ice and multi-phase clouds is shown in Fig. 9.

This leaves us with 8308 water cloud, 97449 ice cloud and 25043 multi-phase cloud pixels for APICS and 14751 water cloud, 75259 ice cloud and 20798 multi-phase cloud pixels for CMSAF. Notice that these numbers are different from those exposed in Sect. 6.2 since we consider three classes here instead of two (see also Table 2).

Evidently, both retrievals are capable of reproducing the real distribution of cloud optical thicknesses $(\tau)$ as can be seen from Fig. 10 which depicts histograms and scatter plots of retrieved and real optical thickness.

As far as APICS is concerned, the distribution of water and ice clouds is better approximated than that for multi-phase clouds as attested in Fig. 10a-c. These panels show histograms of retrieved op-

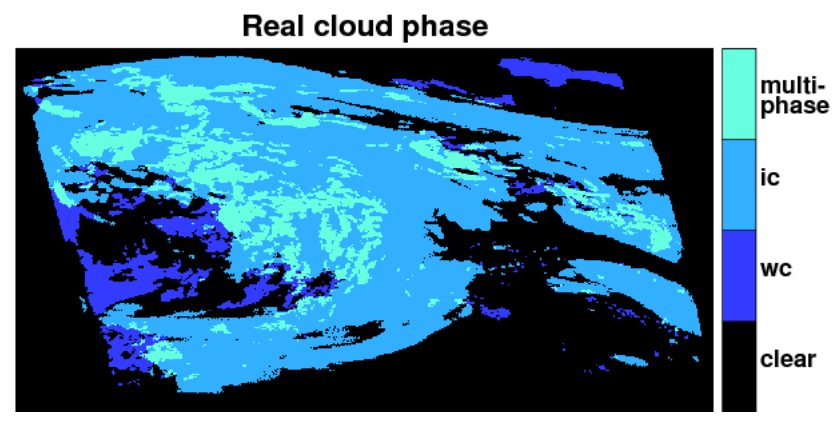

Fig. 9. Real cloud phase on the MET-8/SEVIRI grid: water clouds and ice clouds denote pixels containing exclusively liquid or iced cloud constituents. For an explanation of multi-phase clouds see the text.

tical thickness for the pixels of the common cloud mask (red lines) and histograms of real optical thickness without restrictions to the common mask (green lines). In fact, the histogram peak around optical thickness 10 for multi-phase clouds is more pronounced in the retrieval than in reality. For water clouds, APICS misses the first peak while it overestimates the second one. Plots d-f in Fig. 10 confirm a good correlation between real and retrieved water and ice cloud optical thicknesses (the correlation coefficient is 0.977 and 0.996 respectively). Here of course both retrieved and real values are for pixels of the common cloud mask. Altogether, APICS slightly underestimates real optical thickness: mean differences between retrieved and real cloud optical thickness amount to -0.71 for water and -0.13 for ice clouds, with a standard deviation of 1.20 for water clouds which is higher than for ice clouds (0.37). Multiphase clouds show a worse correlation of 0.957 , a mean underestimation of -6.51 and a larger scattering of 8.76. However, those multi-phase clouds that were treated as water clouds by APICS lie on the one-one line. Finally, relative differences (Fig. 11a) between optical thicknesses of real and retrieved water and ice clouds are both quite sharply peaked around -0.04 while the relative difference distribution of multi-phase clouds is much more flat with a peak around -0.45 .

Considering now CMSAF results (blue lines in Fig. 10a-c), a slightly different behaviour can be observed. The water cloud distribution accounts quite well for the two peaks observed in reality for $\tau \leq 15$ (Fig. 10a). Only the occurrence of thicker clouds ( $\tau \geq 20$ ) is underestimated. For ice clouds (Fig. 10b), CMSAF underestimates the occurrence of thin clouds $(\tau \leq 2)$ and overestimates the occurrence of the remaining clouds $(\tau>2)$. Multi-phase cloud occurrence is well reproduced by CMSAF with a peak at the correct location but with higher magnitude. Scatter plots (Fig. 10g-i) show a good one-to-one correlation for water clouds with a slight tendency to underestimation but with rather high scattering (Fig. 10g). The correlation coefficent between CMSAF and real water cloud optical thicknesses amounts to 0.722 , the mean difference is -1.5 and the standard deviation 5.26. For ice cloud optical thickness underestimations are also observed together with a correlation coefficient of 0.910 . The mean difference of ice cloud optical thickness between CMSAF and reality amounts to -0.38 with a standard deviation of 1.22. Multi-phase clouds (Fig. 10i) show a worse agreement with a larger underestimation as well as a larger scattering (correlation coefficient $=0.802$, mean difference $=-10.27$, standard 

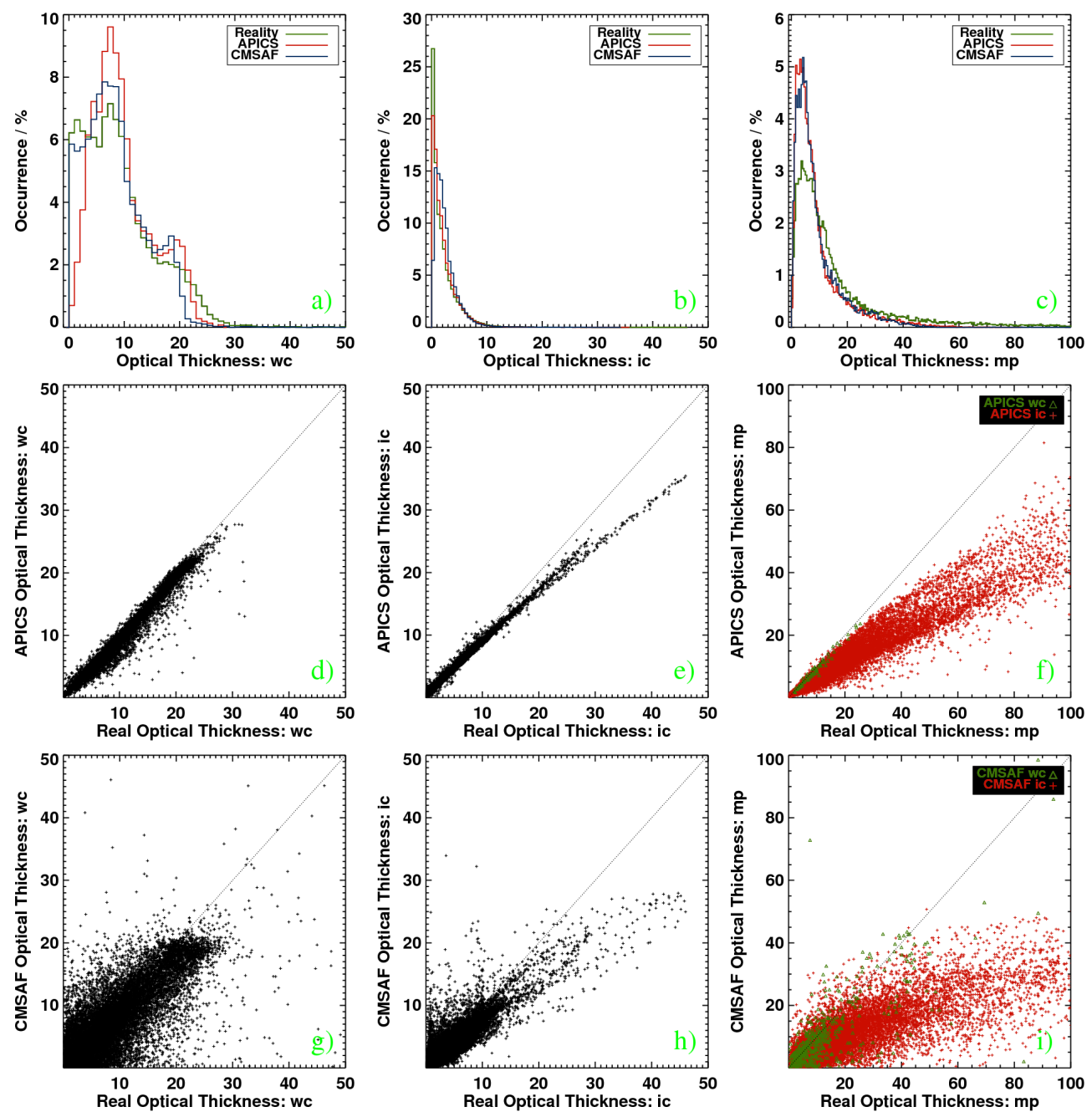

Fig. 10. Histograms and scatter plots of retrieved and real cloud optical thickness for both APICS and CMSAF. (a-c) Histograms of retrieved and real optical thickness of water, ice and multi-phase clouds for both APICS and CMSAF. (d-f) Scatter plots of APICS optical thicknesses against real optical thicknesses for water, ice and multi-phase clouds. (g-i) Scatter plots of CMSAF optical thicknesses against real optical thicknesses for water, ice and multi-phase clouds.

deviation=18.1). In particular, when the multi-phase cloud was classified as a water cloud by CMSAF, a reasonable agreement was found. The distribution of relative differences between optical thicknesses of real and retrieved clouds is shown in Fig. 11a for CMSAF as well. Both water and ice clouds show a peak at around -0.10 while multi-phase clouds confirm the stronger tendency to underestimation already observed in Fig. 10i and in particular the large scattering mentioned above.

Considering the different accuracies of the two (ice cloud) retrievals it must be emphasised that ice cloud properties show a relevant dependence on ice particle shape and the parameterisation of their optical properties. While APICS uses optical properties for hexagonal columns by Key et al. (2002); Yang et al. (2000), CMSAF considers imperfect hexagonal crystals according to Hess et al. (1998). In our reality, also Key et al. (2002); Yang et al. (2000) was used such that APICS had a clear advantage in this case.

\subsection{Cloud effective radius}

Effective radius is a quantity that is particularly difficult to validate for various reasons. In reality effective radius is a function of cloud height in every pixel while spaceborne retrievals usually output one single quantity since they assume the existence of homogeneous plane-parallel clouds inside every pixel. Droplet size information is contained in the $1.6 \mu \mathrm{m}$ MET-8/SEVIRI channel where water droplets not only reflect but also absorb solar radiation. This absorption increases with cloud droplet size: the greater the droplet absorption the less the cloud reflectance. However, these reflectances may also depend on optical thickness such that the value of the effective radius must always be determined at the same time as optical thickness. Optical thickness, on its turn, largely depends on the $0.6 \mu \mathrm{m}$ MET-8/SEVIRI channel where absorption is marginal. However, real-world clouds are usually vertically inhomogeneous 

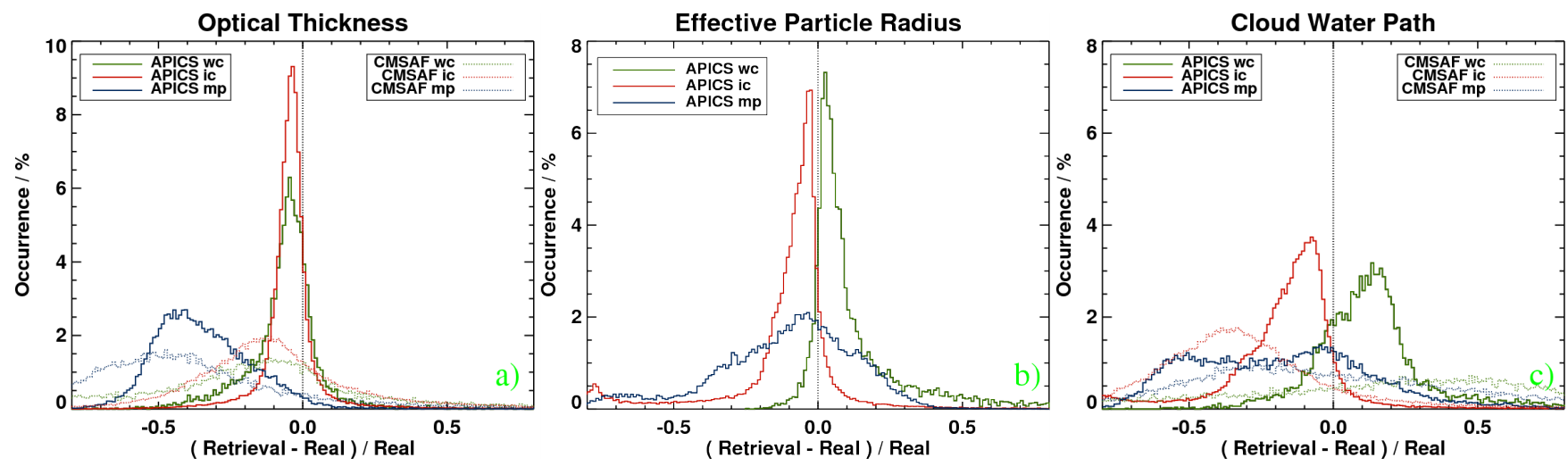

Fig. 11. Histograms of relative differences between retrieved and real cloud optical thickness a), cloud effective radius b) and cloud water path c) for water (green), ice (red) and multi-phase (blue) clouds. Solid lines denote APICS retrieval results, dotted lines CMSAF retrieval results.
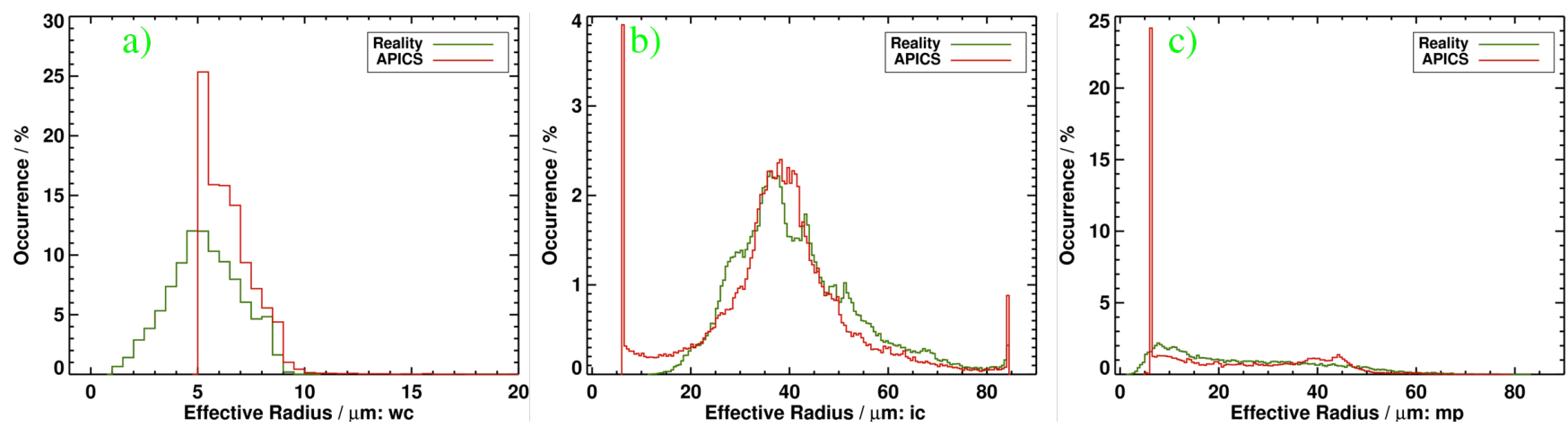

Fig. 12. Histograms of APICS and real cloud effective radius for water (a), ice (b) and multi-phase clouds (c).

and a retrieval gives optical thickness and effective radius of a homogeneous cloud having (nearly) the same spectral reflectances as the measured one. Thus, effective radius does not only depend on the absorbing intensity of the channel used (Platnick, 2000) but is also highly retrieval dependent and there is no real truth to compare with. Nevertheless, one can think of the retrieved effective radius as a weighted mean of the effective radius vertical profile:

$r_{\text {eff, retrieved }}=\int_{z_{\text {top }}}^{z_{\text {bottom }}} r_{\text {eff }}(z) w(z) d z$,

where $z_{\text {top }}$ and $z_{\text {bottom }}$ are the cloud top and bottom height, $r_{\text {eff }}(z)$ is the vertical profile of effective radii and $w(z)$ is the vertical weighting function. According to Platnick (2000), the weighting function $w(z)$ can be thought of as the fraction of scattering events at a given level of the cloud. We tried to mimick the weighting functions presented in Platnick (2000) by considering the scaled optical thickness $\tau_{S}(i)$ of the layer $i=1, \ldots, n l$ ( $n l=$ number of cloud layers) and the accumulated scaled cloud optical thickness $\tau_{\text {acc,s }}(j)$ at level $j=0, \ldots, n l+1$ :

$$
\begin{aligned}
\tau_{S}(i) & =\tau(i) \cdot(1-g(i)) \\
\tau_{\mathrm{acc}, \mathrm{s}}(j) & =\sum_{i=1}^{j} \tau_{S}(i), \quad j \in[1, n l+1] \\
\tau_{\mathrm{acc}, \mathrm{s}}(0) & =0
\end{aligned}
$$

with $g(i)$ being the asymmetry parameter of layer $i$ and $\tau(i)$ the optical thickness of layer $i=1, \ldots, n l$ (at $550 \mathrm{~nm}$ ). The retrieved effective radius is defined as

$r_{\text {eff, retrieved }}=\frac{1}{C} \sum_{j=0}^{n l 8-1} \exp \left(-\tau_{\mathrm{acc}, \mathrm{s}}(j)\right) \cdot \tau_{s}(j+1) \cdot r_{\mathrm{eff}}(i+1)$,

where $r_{\mathrm{eff}}(i)$ is the effective radius of layer $i$. The upper limit of the sum $n l 8$ is the layer number such that $\tau_{\mathrm{acc}, \mathrm{s}}(n l 8+1)=8$. The value of 8 is taken from Platnick (2000) as well, but the results are not very sensitive to it because the exponential in Eq. (7) decreases very fast as a function of the accumulated scaled optical thickness. The factor $C$ is a normalisation constant that amounts to

$C=\sum_{j=0}^{n l 8-1} \exp \left(-\tau_{\mathrm{acc}, \mathrm{s}}(j)\right) \cdot \tau_{s}(j+1)$.

This way, we could assign an effective radius to each simulated cloud column. Effective radii for all MET-8/SEVIRI pixels can then be obtained by projection to the satellite grid. Figure 12 shows histograms of retrieval results and real properties for water, ice and multi-phase clouds. The selection of pixels corresponds to that of Sect. 6.4 where optical thickness was discussed.

Water clouds mainly contain small effective radii (see Table 2). This might be due to the specific weather situation, with only few 

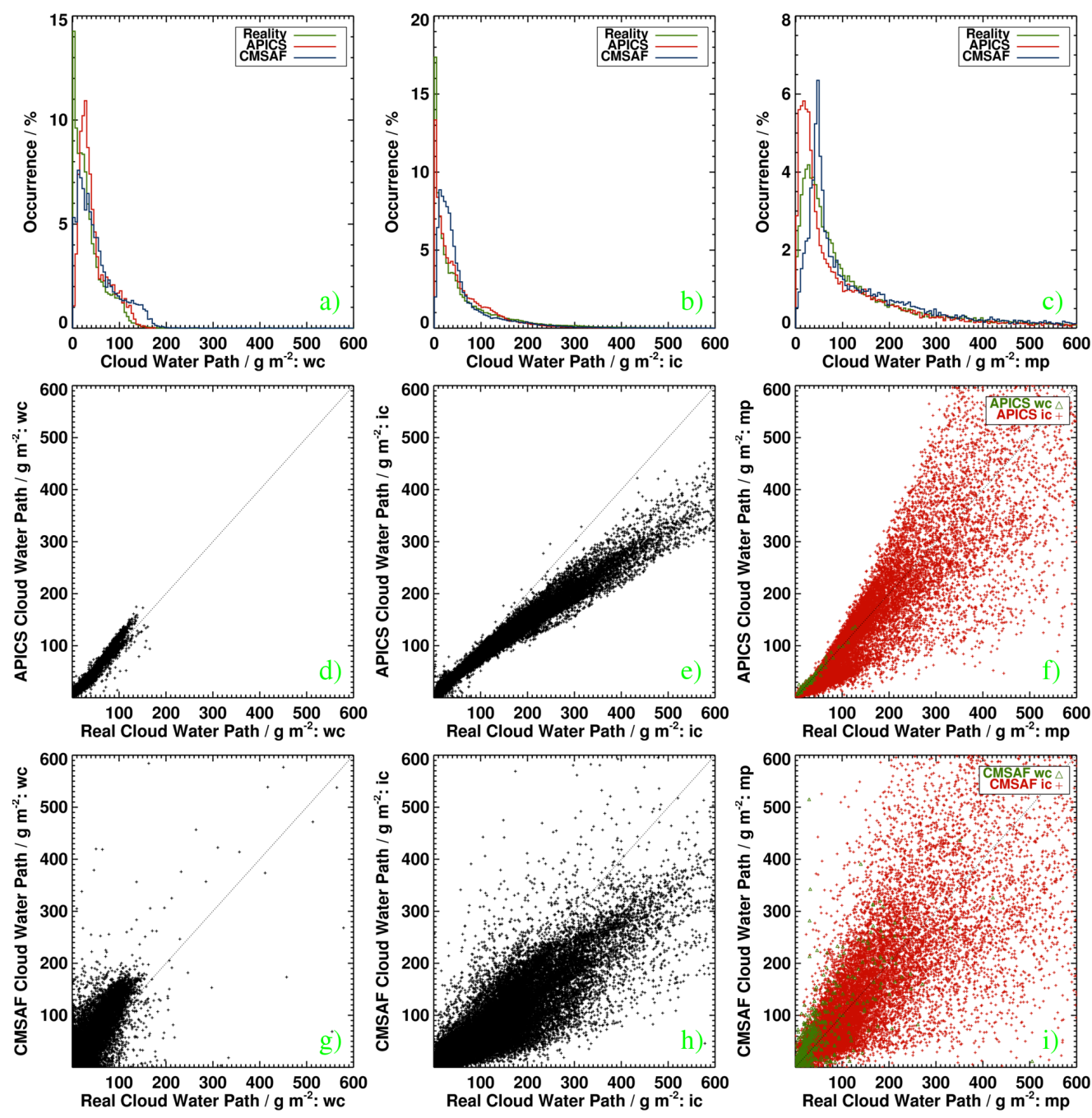

Fig. 13. Histograms and scatter plots of retrieved and real cloud water path for both APICS and CMSAF. (a-c) Histograms of retrieved and real cloud water path of water, ice and multi-phase clouds for both APICS and CMSAF. (d-f) Scatter plots of APICS cloud water path against real cloud water path for water, ice and multi-phase clouds. (g-i) Scatter plots of CMSAF cloud water path against real cloud water path for water, ice and multi-phase clouds.

liquid water clouds visible from above, and is mirrored in the occurrence distribution of $r_{\text {eff }}$ as retrieved by APICS and in nature (Fig. 12a). Many of the clouds butt at the lower bound of the range permitted by the APICS algorithm and accumulate at $5 \mu \mathrm{m}$. For this reason, the correlation coefficient of the two data sets is 0.633 and the mean relative difference 0.17 .

Ice clouds, depicted in Fig. 12b, show that APICS produces two peaks at the smallest and largest effective radius 6 and $84 \mu \mathrm{m}$ respectively although no cloud box is present with such a small or large effective radius (Table 2). The third APICS peak around $40 \mu \mathrm{m}$ coincides very well with the real one, and both effective radius distributions (APICS and real) agree quite nicely with a correlation coefficient of 0.726 (mean relative difference $=-0.10$ ). Multi-phase clouds (Fig. 12c) are characterised by a flat (homogeneous) distribution of effective radii. APICS shows a high occurrence of the smallest effective radii, which is probably due to the fact that this cloud type is not correctly represented in the retrieval look-up tables. The correlation coefficient is 0.922 (mean relative difference $=-0.11$ ).

\subsection{Cloud water path}

Again, we restrict the validation to those pixels that belong to the common cloud mask for APICS and CMSAF separately. Furthermore, like in Sects. 6.4 and 6.5 we consider the three classes of water, ice and multi-phase clouds (see Sect. 6.4 for an explanation). For APICS, we have 8308 water cloud, 97449 ice cloud and 25043 multi-phase cloud pixels. For CMSAF, this leaves us with 14751 water cloud, 75259 ice cloud and 20798 multi-phase cloud pixels.

Evidently, both retrievals are capable of reproducing the real distribution of cloud water path (CWP) for liquid and ice water clouds (Fig. 13a and b), although with some scattering.

APICS' liquid water path (LWP) is slightly shifted towards larger values with respect to reality, but this is especially true 
for small LWPs (Fig. 13a). The occurrence of very small LWPs $\left(<30 \mathrm{~g} \mathrm{~m}^{-2}\right)$ is largely underestimated: the peak of real LWPs located at $10 \mathrm{~g} \mathrm{~m}^{-2}$ is missed. For ice clouds (Fig. 13b), the peak of occurrences is underestimated but its location is correct, as well as the decrease of the histogram curve for increasing ice water path (IWP) values. The mixed-phase class is characterised by a broad peak for small cloud water path values $\left(\leq 40 \mathrm{~g} \mathrm{~m}^{-2}\right)$ that is overestimated by APICS. In the range $40-150 \mathrm{~g} \mathrm{~m}^{-2}$ APICS values are then larger than real values while the distribution of the remaining CWPs $\left(>150 \mathrm{~g} \mathrm{~m}^{-2}\right)$ almost coincide. In the scatter plots (Fig. 13d-f) APICS' LWP shows a good correspondence to real values although the data point cloud seems to possess two branches: one showing a slight overestimation and one showing a slight underestimation (correlation coefficient $=0.976$, mean absolute difference $=3.97 \mathrm{~g} \mathrm{~m}^{-2}$, standard deviation $=6.694 \mathrm{~g} \mathrm{~m}^{-2}$ ). APICS retrieves small ice water paths $\left(<100 \mathrm{~g} \mathrm{~m}^{-2}\right)$ correctly while larger values are overestimated (correlation coefficient $=0.977$, mean absolute difference $=-16.5 \mathrm{~g} \mathrm{~m}^{-2}$, standard deviation $=45.24 \mathrm{~g} \mathrm{~m}^{-2}$ ). Cloud water paths for mixed-phase clouds produce the largest scattering around the one-one line (correlation coefficient $=0.892$, mean absolute difference $=-23.2 \mathrm{~g} \mathrm{~m}^{-2}$, standard deviation $=122.5 \mathrm{~g} \mathrm{~m}^{-2}$ ).

CMSAF's LWP (Fig. 13a) occurrences are similar to APICS' and reproduce quite well the real LWP distribution, apart from the fact that the location of the histogram peak is slightly overestimated while the height of this peak is underestimated. In addition, the use of default values in the CMSAF scheme gives rise to the peak at $510 \mathrm{~g} \mathrm{~m}^{-2}$. The IWPs (Fig. 13b) obtained by CMSAF reproduce reality quite exactly for values larger than $100 \mathrm{~g} \mathrm{~m}^{-2}$. The occurrence of small IWPs is underestimated, with a CMSAF histogram peak at approximately $50 \mathrm{~g} \mathrm{~m}^{-2}$. Mixed-phase clouds show a somehow similar behaviour: the distribution of CWPs larger than $50 \mathrm{~g} \mathrm{~m}^{-2}$ is very well accounted for by CMSAF. The occurrence of small values $\left(<30 \mathrm{~g} \mathrm{~m}^{-2}\right)$ is underestimated and the CMSAF histogram peaks strongly at $40 \mathrm{~g} \mathrm{~m}^{-2}$. Plots in Fig. $13 \mathrm{~h}-\mathrm{i}$ confirm a fairly good correlation $(0.749$ and 0.903$)$ between real and retrieved water and ice clouds respectively. At the same time, a tendency to overestimation is shown for water clouds and to underestimation for ice clouds. This is reflected in the mean differences between retrieved and real cloud water path: $14.35 \mathrm{~g} \mathrm{~m}^{-2}$ for water and $-33.8 \mathrm{~g} \mathrm{~m}^{-2}$ for ice clouds, with a standard deviation of $31.18 \mathrm{~g} \mathrm{~m}^{-2}$ for water clouds and $62.51 \mathrm{~g} \mathrm{~m}^{-2}$ for ice clouds. The scatter plot of CMSAF against real ice water path in Fig. 13i also shows a structure that might be related to the four ice cloud models used in the compilation of the look-up tables for the retrieval (see Sect. 5.2.3). Multi-phase clouds show a correlation of 0.742 , a mean overestimation of $-30.6 \mathrm{~g} \mathrm{~m}^{-2}$ and a larger scattering of $235.9 \mathrm{~g} \mathrm{~m}^{-2}$.

Relative differences (Fig. 11c) between cloud water paths of real and APICS water clouds are peaked around 0.2, ice clouds are peaked at -0.1 , while the relative difference distribution of multiphase clouds shows a shallow maximum around -0.05. Apart from ice clouds with a peak between -0.4 and -0.3 , CMSAF shows distributions that are quite broad with no clear peak. The worse performance of CMSAF with respect to cloud optical thickness must be due to the effective radius retrieval.

\section{Conclusions}

Based on three-dimensional cloud distributions from the COSMOEU model and a downscaling procedure, a cloud data set has been produced with a resolution of $2.33 \mathrm{~km}$ appropriate for the simulation of SEVIRI radiometer observations aboard the geostationary european MET-8 satellite (MSG-1). These clouds were input to detailed bias-free one-dimensional radiative transfer calculations to produce a realistic synthetic MET-8/SEVIRI satellite scene. In this exercise, the channels were assumed to be perfectly calibrated and instrumental noise was not considered.

The outcome of this study is a unique data set for the validation of retrieval algorithms of atmospheric, cloud, and surface properties from Meteosat Second Generation. Using the known cloud properties as a reference (i.e. as reality), we could quantitatively validate the outcome of two cloud retrieval algorithms in a closed-loop test where both input and output data sets are known.

The APICS and CMSAF cloud retrieval algorithms applied here for illustration purposes both proved to be able to satisfactorily reproduce the cloud distribution and its properties although some of them could be better retrieved than other. As far as cloud detection is concerned, APICS' largest inaccuracy consisted in a misclassified (i.e. inexistent) cirrus cloud field while the CMSAF algorithm had difficulties when dealing with cloud edges.

Cloud top temperatures could also be retrieved in a correct way throughout but a large variability was shown. For instance, APICS overestimated some cirrus cloud edges while it underestimated some other cirrus field. CMSAF instead had difficulties with the same cirrus cloud edges and also some water clouds.

For cloud optical thickness one has to differentiate between water and ice clouds. For water clouds, where the underlying optical properties were parameterised with Mie theory, a good agreement between reality and retrieval was observed, although CMSAF's scattering was slightly larger than APICS'. For ice clouds, where apriori assumptions about shape and composition are required, the agreement between reality and model was slightly worse for CMSAF. APICS, which used the same ice optical properties parameterisation "as the real clouds", had a strong advantage and reproduced ice optical thicknesses fairly well but with a tendency to underestimation. CMSAF used a different parameterisation for ice crystal optical properties and nevertheless it could derive ice cloud optical thickness in a good way but with some scattering. As expected, pixels containing both water and ice clouds caused the largest inaccuracies and the largest scattering of results for both retrievals.

Cloud particle effective radius is difficult to evaluate since it changes with height inside real clouds while retrieval algorithms obtain a single value representative of the upper part of the vertical profile. Thus, we used a weighting of the vertical profiles of effective radii to first extract one quantity to be used in the comparison with the APICS cloud scheme. Since the distribution of liquid water droplet effective radii contains many values below $5 \mu \mathrm{m}$, the lower detection limit of APICS, the correlation between APICS and reality is moderate. The agreement between APICS and real effective radii for ice and mixed-phase clouds is instead very good. Nevertheless, unrealistic peaks at the lowest and highest limits of the detection range could also be observed.

The cloud water path APICS retrieval proved to be quite reliable, especially for water and ice clouds. Although CMSAF derived quite accurate cloud optical thicknesses, cloud water paths were less reliable probably because of the accuracy of the effective 
radius retrieval and because of the larger scattering observed in CMSAF optical thickness with respect to reality. Please notice that the version of the CPP algorithm currently operated at CMSAF is more advanced than the one used in this study and is likely to produce improved results.

The proposed validation technique is thus a powerful tool for detailed investigations of the performance of satellite retrievals because objective information about clouds is available. Since it is based on accurate radiative transfer calculations its basis is sound. However, the underlying cloud model plays an important role: although large scale cloud structures are realistic and consistent with the ambient conditions thanks to the COSMO-EU weather model, the small scale cloud variability is underestimated as the horizontal resolution is limited to $2.33 \mathrm{~km}$. Furthermore, ice crystal size distribution as well as ice crystal shape have been arbitrarily selected to produce an input data set for the radiative transfer simulations. As far as the choice of ice particle size distribution is concerned, Rolland et al. (2000) observe a retrieval uncertainty in optical thickness of 1-3\%. For particle shape, the situation is different. Here, different particle shapes produces different phase functions. From first principles, largest differences are expected for thin cirrus clouds where single scattering effects play a major role and directly reflect the shape of the phase function. For thicker clouds, vanishing effects are expected. In fact, Rolland et al. (2000) show that ice particle shape produces uncertainties up to $5 \%$ for optical thicknesses in the range between 0.1 and 8 , and between 10 and $20 \mu \mathrm{m}$ for mean effective particle diameters $D_{\text {eff }}\left(D_{\text {eff }}=2 r_{\text {eff }}\right)$ in the range $20-100 \mu \mathrm{m}$. In the thermal spectral range, Baran (2005) considers hexagonal columns and aggregates and 30 different size ditributions. He shows first that the effect of size distribution is negligible for wavelengths smaller than $10-15 \mu \mathrm{m}$ but must be considered for wavelengths larger than $20 \mu \mathrm{m}$. He also shows that for the thermal MSG/SEVIRI channels the magnitude of the brightnesstemperature difference between the two ice crystal shapes considered is at most $2 \mathrm{~K}$ but decreases towards zero for optical thicknesses larger than 8 . These results are confirmed by Dubuisson et al. (2008) who investigated the effect of cloud particle shape for the IIR (Imaging Infrared Radiometer) aboard CALIPSO. Thus, the effect on the retrieval of cloud top temperature should be in the order of $1 \%$, thus negligible. In this study we selected hexagonal columns in all ice cloud boxes. Of course, retrievals that are consistent with this choice have a clear advantage in retrieving ice crystal effective radius, APICS in this case. However, also the findings about the performance of CMSAF are of interest. With our procedure, we know that ice particle shapes are different in the retrieval and in our reality. In contrast, the representation of water cloud optical and microphysical properties is not arbitrary and is based on the exact Mie theory for spherical water droplets. The optical properties are then determined by the effective droplet radius. The shape of the water droplet size distribution function inside each box is not important. It has only an effect on the radiances for specific scattering angles corresponding for instance to the glory (backscatter region). In these conditions it is even possible to derive the width of the particle size distribution (Mayer et al., 2004). To this end, however, either high spatial resolutions are needed or clouds that are homogeneous over the entire observed region, i.e. in our case over the entire satellite pixel. For MSG/SEVIRI, the size of a pixel over Europe is of the order of $15-20 \mathrm{~km}^{2}$ which considerably reduces the possibility that such effects can be observed. In the thermal spectral range cloud size distribution plays no role such that cloud top temperature is not affected.

Another issue is surface albedo: we used data from spaceborne measurements, and if a retrieval assumes the same a-priori surface albedo it certainly has an advantage compared to a completely independent retrieval. This, however, is only true in the case of thin (mainly ice) clouds.

Finally we did not consider real-world issues like inaccurate calibration, noise, incorrect geolocation, channel cross-talk, imprecise interchannel registration, or sensor saturation. All these effects have been excluded from the simulation since we intended to study the performance of the retrievals and assess deficiencies inherent to them which are not produced by external, instrument-related factors. On the other side, every cloud retrieval algorithm has eventually to deal with real data and is designed to cope with all these aspects. This means that the performance of the investigated retrievals when applied to real satellite measurements may slightly differ from the one that is obtained in this study. Instrument-related effects could be quantified in a separate study. It has to be noted that - since retrieval algorithms are often tuned by the actual satellite observations (especially cloud detection schemes) - their performance when applied to real data could be better than when applied to the bias-free simulations produced in this study.

All these things considered, the proposed validation method for spaceborne retrievals is a powerful tool. Since all parameters used in the simulation are realistic and typical for the selected day and time, all retrievals should be able to produce meaningful results. Of course, "free" parameters like ice crystal shape will lead to some uncertainty in the retrieval output and schemes that are fully consistent with the simulation apparatus will have an advantage.

In summary, we have shown the potential of this method for the evaluation of spaceborne algorithms and recommend its usage to the scientific retrieval community as one possible effective way to test and tune algorithms. Conceivable applications of this approach are manifold: (a) the quantitative evaluation of further satellite algorithms as shown here; (b) investigations about the impact of different NWP models (for the extraction of the ancillary data needed by the retrieval schemes) on the retrieved quantities, in particular cloud top temperatures; (c) studies about the uncertainty of calibration accuracy on the retrieved (cloud) properties; (d) implications of point spread functions for spaceborne retrievals; (e) effect of solar geometry on retrievals; (f) impact of ice cloud particle shape on retrieved cloud optical properties. In future, we will also include the effect of the one-dimensional radiative transport approximation usually made in the retrievals. Furthermore, by simulating the same scene from the point of view of a polar orbiting and a geostationary satellite, synergistic effects could be examined in a detailed quantitative way. 


\section{Appendix A}

\section{Simulation Results}

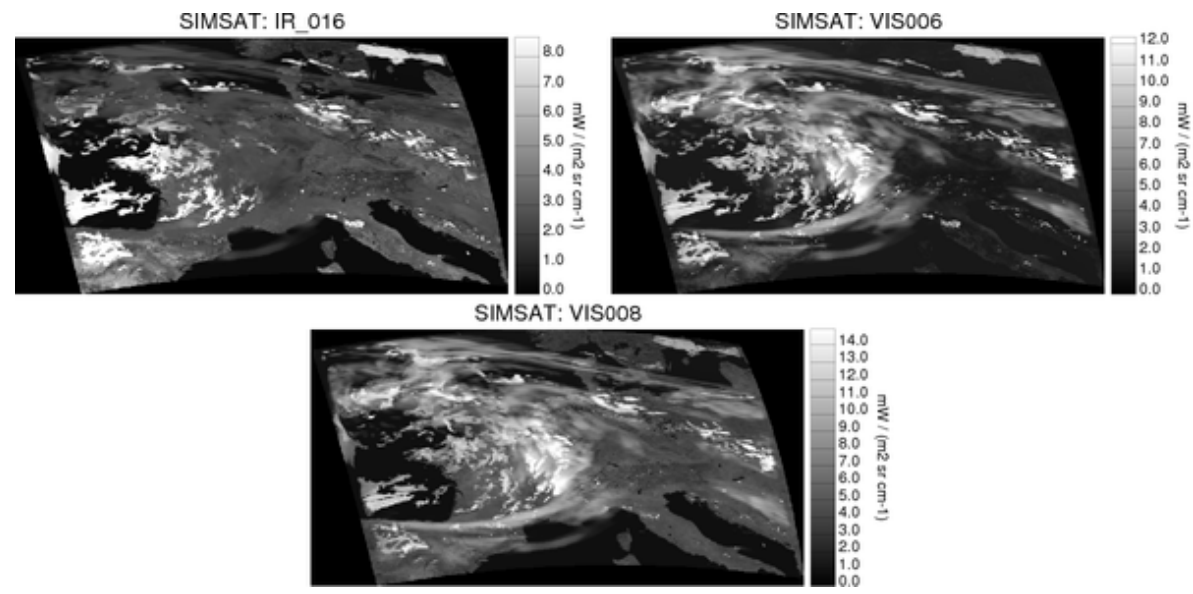

Fig. A1. Solar SEVIRI radiances computed with libRadtran and projected onto the nominal MET-8/SEVIRI grid under consideration of the MET-8/SEVIRI point spread functions.

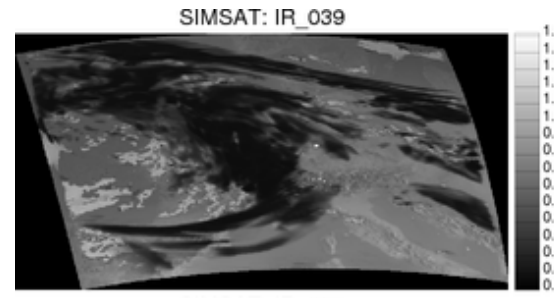

SIMSAT: IR 097
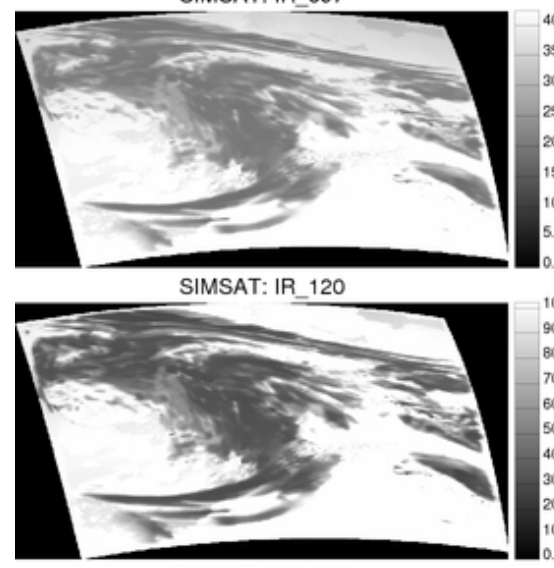

SIMSAT: WV 062

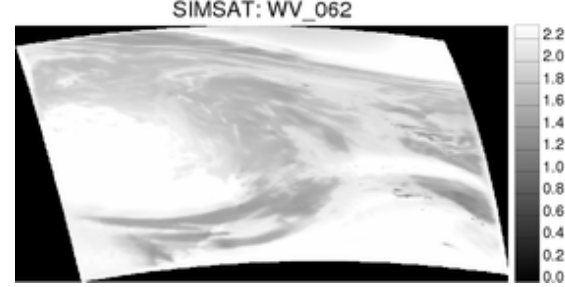

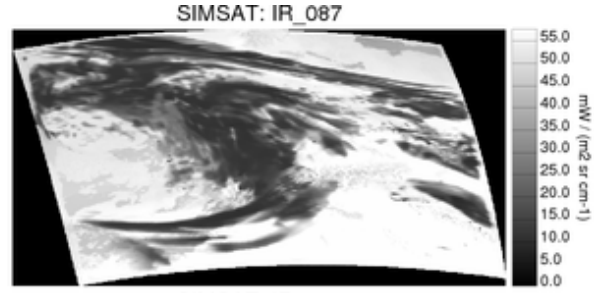

SIMSAT: IR_108

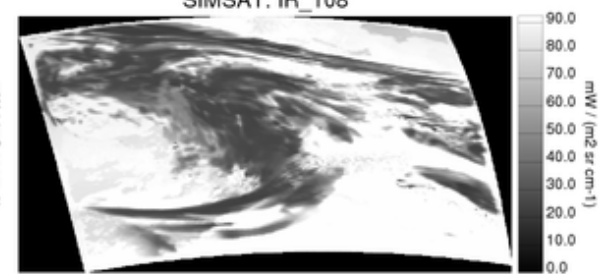

SIMSAT: IR_134

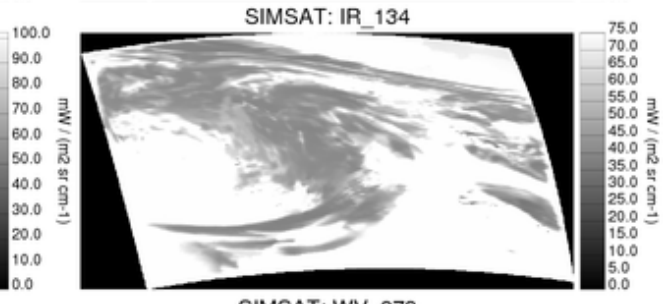

SIMSAT: WV 073

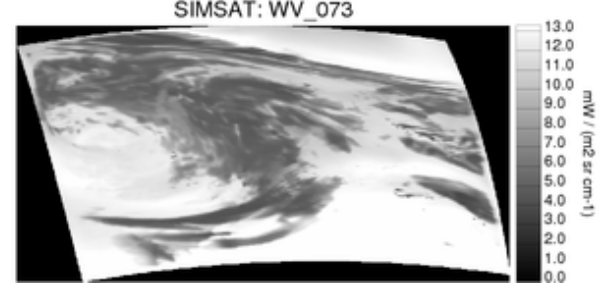

Fig. A2. Thermal SEVIRI radiances computed with libRadtran and projected onto the nominal MET-8/SEVIRI grid under consideration of the MET-8/SEVIRI point spread functions. 
Acknowledgements. The study was funded by the Satellite Application Facility on Climate Monitoring (CM-SAF) which is hosted by Deutscher Wetterdienst (DWD). We thank Arnold Tafferner (DLR) for careful reading of the manuscript and valuable comments, and Phil Watts (EUMETSAT) for detailed reading of the ACP Discussions publication and constructive criticism that improved the quality of the paper.

Edited by: P. Stier

\section{References}

Anderson, G., Clough, S., Kneizys, F., Chetwynd, J., and Shettle, E.: AFGL Atmospheric Constituent Profiles (0-120 km), Tech. Rep. AFGL-TR-86-0110, AFGL (OPI), Hanscom AFB, MA 01736, 1986.

Baran, A. J.: The dependence of cirrus infrared radiative properties on ice crystal geometry and shape of the sizedistribution function, Q. J. Roy. Meteorol. Soc., 131, 1129-1142, doi:10.1256/qj.04.91, 2005.

Baum, B., Soulen, P., Strabala, K., King, M., Ackerman, S., Menzel, W., and Yang, P.: Remote sensing of cloud properties using MODIS airborne simulator imagery during SUCCESS. 2. Cloud thermodynamic phase, J. Geophys. Res., 105, 1178111792, 2000.

Cayla, F. and Tomassini, C.: Détermination de la température des cirrus semitransparents, La Météorologie, 15, 63-67, 1978.

Chahine, M.: Remote sounding of cloudy atmospheres, I, The single cloud layer, J. Atmos. Sci., 31, 233-243, 1974.

Clerbaux, N., Dewitte, S., Gonzalez, L., Bertrand, C., Nicula, B., and Ipe, A.: Outgoing longwave flux estimation: improvement of angular modelling using spectral information, Remote Sens. Environ., 85, 389-395, 2003.

Cox, C. and Munk, W.: Measurement of the roughness of the sea surface from photographs of the sun's glitter, J. Opt. Soc. USA, 44, 838-850, 1954a.

Cox, C. and Munk, W.: Statistics of the sea surface derived from sun glitter, J. Marine Res., 13, 198-227, 1954b.

Davis, R.: Comparison of modeled to observed global irradiance, J. Appl. Meteorol., 35, 192-201, 1996.

DeBacker, H., Koepke, P., Bais, A., de Cabo, X., Frei, T., Gillotay, D., Haite, C., Heikkilä, A., Kazantzidis, A., Koskela, T., Kyrö, E., Lapeta, B., Lorente, J., Masson, K., Mayer, B., Plets, H., Redondas, A., Renaud, A., Schauberger, G., Schmalwieser, A., Schwander, H., and Vanicek, K.: Comparison of measured and modelled UV indices, Meteorol. Appl., 8, 267-277, 2001.

de Haan, J. F., Bosma, P. B., and Hovenier, J. W.: The adding method for multiple scattering calculations of polarized light, Astronom. Astrophys., 183, 371-391, 1987.

Derrien, M. and LeGleau, H.: MSG/SEVIRI cloud mask and type from SAFNWC, Int. J. Remote Sens., 26, 4707-4732, 2005.

Dubuisson, P., Giraud, V., Pelon, J., Cadet, B., and Yang, P.: Sensitivity of Thermal Infrared Radiation at the Top of the Atmosphere and the Surface to Ice Cloud Microphysics, J. Appl. Meteorol. Climatol., 47, 2545-2560, doi:10.1175/2008JAMC1805.1, 2008.

EUMETSAT: A Planned Change to the MSG Level $1.5 \mathrm{Im}-$ age Product Radiance Definition, Technical Notes EUM/OPSMSG/TEN/06/0519, 2007.
Eyre, J. and Menzel, P.: Retrieval of Cloud Parameters from Satellite Sounder Data: A Simulation Study, J. Appl. Meteorol., 28, 267-275, 1989.

Ham, S.-H., Sohn, B.-J., Yang, P., and Baum, B. A.: Assessment of the Quality of MODIS Cloud Products from Radiance Simulations, J. Appl. Meteorol. Climatol., 48, 1591-1612, doi:10.1175/2009JAMC2121.1, 2009.

Hansen, J. and Travis, L.: Light scattering in planetary atmospheres, Space Sci. Rev., 16, 527-610, 1974.

Hanssen, A. W. and Kuipers, W.: On the relationship between the frequency of rain and various meteorological parameters, Koninklijk Ned. Meteor. Instit., Meded. Verhand., 2-15, 1965.

Hess, M., Koepke, P., and Schult, I.: Optical properties of aerosols and clouds: the software package OPAC, B. Am. Meteorol. Soc., 79, 831-844, 1998.

Key, J., Yang, P., Baum, B., and Nasiri, S.: Parameterization of shortwave ice cloud optical properties for various particle habits, J. Geophys. Res., 107(D13), 4181, doi:10.1029/2001JD000,742, 2002.

Kokhanovsky, A. A., Deuzé, J. L., Diner, D. J., Dubovik, O., Ducos, F., Emde, C., Garay, M. J., Grainger, R. G., Heckel, A., Herman, M., Katsev, I. L., Keller, J., Levy, R., North, P. R. J., Prikhach, A. S., Rozanov, V. V., Sayer, A. M., Ota, Y., Tanré, D., Thomas, G. E., and Zege, E. P.: The inter-comparison of major satellite aerosol retrieval algorithms using simulated intensity and polarization characteristics of reflected light, Atmos. Meas. Tech., 3, 909-932, doi:10.5194/amt-3-909-2010, 2010.

Krebs, W., Mannstein, H., Bugliaro, L., and Mayer, B.: Technical note: A new day- and night-time meteosat second Generation Cirrus Detection Algorithm MeCiDA, Atmos. Chem. Phys., 7, 6145-6159, doi:10.5194/acp-7-6145-2007, 2007.

Kriebel, K.-T., Gesell, G., Kästner, M., and Mannstein, H.: The cloud analysis tool APOLLO: improvements and validation, Int. J. Remote Sens., 24, 2389-2408, 2003.

Lutz, H.-J.: Cloud processing for Meteosat Second Generation, Tech. memo. 4, EUMETSAT Tech. Department, 1999.

Lutz, H.-J.: Scenes analysis from MODIS and Meteosat observations, in: Proceedings of The 2002 EUMETSAT Meteorological Satellite Data Users' Conference, 2002.

Lutz, H.-J., Inoue, T., and Schmetz, J.: Comparison of split-window and a multi-spectral cloud classification for MODIS observations, J. Meteorol. Soc. Jpn., 81, 623-631, 2003.

Majewski, D.: The new global icosahedral-hexagonal grid point model GME of the Deutscher Wetterdienst, in: Recent developments in numerical methods for atmospheric modelling, ECMWF, Seminar Proceedings, 173-201, 1998.

Majewski, D., Liermann, D., Prohl, P., Ritter, B., Buchhold, M., Hanisch, T., Paul, G., Wergen, W., and Baumgardner, J.: The Operational Global Icosahedral-Hexagonal Gridpoint Model GME: Description and High-Resolution Tests, Mon. Weather Rev., 130, 319-338, 2002.

Martin, G., Johnson, D., and Spice, A.: The measurement and parameterization of effective radius of droplets in warm stratocumulus clouds, J. Atmos. Sci., 51, 1823-1842, 1994.

Mayer, B. and Kylling, A.: Technical Note: The libRadtran software package for radiative transfer calculations: Description and examples of use, Atmos. Chem. Phys., 5, 1855-1877, doi:10.5194/acp-5-1855-2005, 2005.

Mayer, B., Seckmeyer, G., and Kylling, A.: Systematic long-term 
comparison of spectral UV measurements and UVSPEC modeling results, J. Geophys. Res., 102, 8755-8767, 1997.

Mayer, B., Schröder, M., Preusker, R., and Schüller, L.: Remote sensing of water cloud droplet size distributions using the backscatter glory: a case study, Atmos. Chem. Phys., 4, 12551263, doi:10.5194/acp-4-1255-2004, 2004.

Mayer, B., Vázquez-Navarro, M., and Mannstein, H.: A fast method for the retrieval of integrated longwave and shortwave top-ofatmosphere irradiances from MSG/SEVIRI (RRUMS), Atmos. Meas. Tech. Discuss., to be submitted, 2011.

McFarquhar, G., Iacobellis, S., and Somerville, R.: SCM simulations of tropical ice clouds using observationally based parameterizations of microphysics, J. Climate, 16, 1643-1664, 2003.

Meirink, J., Roebeling, R., Wolters, E., and Deneke, H.: Cloud Physical Products AVHRR / SEVIRI, Algorithm Theoretical Basis Document SAF/CM/KNMI/ATBD/CPP 1.0, 12.2.2010, EUMETSAT SAF on Climate Monitoring, 2010.

Menzel, W., Smith, W., and Stewart, T.: Improved cloud motion wind vector and altitude assignment using VAS, J. Appl. Meteorol., 22, 377-384, 1983.

Menzel, W., Wylie, D., and Strabala, K.: Seasonal and diurnal changes in cirrus clouds as seen in four years of observations with the VAS, J. Appl. Meteorol., 31, 370-385, 1992.

Minnis, P., Liou, K.-N., and Takano, Y.: Inference of cirrus cloud properties using satellite-observed visible and infrared radiances. Part I: Parameterization of radiance fields, J. Atmos. Sci., 50, 1279-1304, 1993.

Nakajima, T. and King, M.: Determination of the optical thickness and effective particle radius of clouds from reflected solar radiation measurements. Part I: Theory, J. Atmos. Sci., 47, 18781893, 1990.

Nakajima, T. and Nakajima, T.: Wide-area determination of cloud microphysical properties from NOAA AVHRR measurements for FIRE and ASTEX regions, J. Atmos. Sci., 52, 4043-4059, 1995.

Nakajima, T. and Tanaka, M.: Effect of wind-generated waves on the transfer of solar radiation in the atmosphere-ocean system, J. Quant. Spectrosc. Radiat. Transfer, 29, 521-537, 1983.

Nieman, S., Schmetz, J., and Menzel, W.: A comparison of several techniques to assign heights to cloud tracers, J. Appl. Meteorol., 32, 1559-1568, 1993.

Otkin, J. A., Posselt, D. J., Olson, E. R., Huang, H.-L., Davies, J. E., Li, J., and Velden, C. S.: Mesoscale Numerical Weather Prediction Models Used in Support of Infrared Hyperspectral Measurement Simulation and Product Algorithm Development, J. Atmos. Ocean. Technol., 24, 585-601, doi:10.1175/JTECH1994.1, 2007.

Pierluissi, J. and Peng, G.-S.: New molecular transmission band models for LOWTRAN, Opt. Eng., 24, 541-547, 1985.

Pinsky, M. and Khain, A.: Fine structure of cloud droplet concentration as seen from Fast-FSSP measurements. Part II: Results of in-situ observations, J. Appl. Meteorol., 42, 65-73, 2003.

Platnick, S.: Vertical photon transport in cloud remote sensing problems, J. Geophys. Res., 105, 22919-22935, 2000.

Reuter, M., Thomas, W., Albert, P., Lockhoff, M., Weber, R., Karlsson, K.-G., and Fischer, J.: The CM-SAF and FUB Cloud Detection Schemes for SEVIRI: Validation with Synoptic Data and Initial Comparison with MODIS and CALIPSO, J. Appl. Meteorol. Climatol., 48, 301-316, doi:10.1175/2008JAMC1982.1, 2009.
Ricchiazzi, P., Yang, S., Gautier, C., and Sowle, D.: SBDART: A research and Teaching software tool for plane-parallel radiative transfer in the Earth's atmosphere, B. Am. Meteorol. Soc., 79, 2101-2114, 1998.

Roebeling, R., Feijt, A., and Stammes, P.: Cloud property retrievals for climate monitoring: Implications of differences between Spinning Enhanced Visible and Infrared Imager (SEVIRI) on METEOSAT- 8 and Advanced Very High Resolution Radiometer (AVHRR) on NOAA-17, J. Geophys. Res., D20210, 111, doi:10.1029/2005JD006990, 2006.

Rolland, P., Liou, K., King, M., Tsay, S., and McFarquhar, G.: Remote sensing of optical and microphysical properties of cirrus clouds using Moderate-Resolution Imaging Spectroradiometer channels: Methodology and sensitivity to physical assumptions, J. Geophys. Res., 105, 11721-11738, 2000.

Rossow, W. and Schiffer, R.: Advances in understanding clouds from ISCCP, B. Am. Meteorol. Soc., 80, 2261-2287, 1999.

SAFNWC: Product User Manual for Cloud Products (CMa-PGE01, CT-PGE02 \& CTTH-PGE03 v1.4), SAF/NWC/CDOP/MFL/SCI/PUM/01 Issue 1, Rev. 4, 7 November 2007, Météo-France, applicable to SAFNWC/MSG version 2008, 2007.

Saunders, R. and Kriebel, K.: An improved method for detecting clear sky and cloudy radiances from AVHRR data, Int. J. Remote Sens., 9, 123-150, 1988.

Saunders, R., English, S., Rayer, P., Matricardi, M., Chevallier, F., Brunel, P., and Deblonde, G.: RTTOV-7: A Satellite Radiance Simulator for the New Millennium, in: Tech. Proc. ITSC-XII Lorne, 27 Feb-5 Mar 2002, 2002.

Schaaf, C., Gao, F., Strahler, A., Lucht, W., Li, X., Tsang, T., Strugnell, N., Zhang, X., Jin, Y., Muller, J.-P., Lewis, P., Barnsley, M., Hobson, P., Disney, M., Roberts, G., Dunderdale, M., Doll, C., d'Entremont, R., Hu, B., Liang, S., and Privette, J.: First Operational BRDF, Albedo and Nadir Reflectance Products from MODIS, Remote Sens. Environ., 83, 135-148, 2002.

Schmetz, J., Holmlund, K., Hoffman, J., Strauss, B., Mason, B., Gaertner, V., Koch, A., and van de Berg, L.: Operational cloudmotion winds from Meteosat infrared images, J. Appl. Meteorol., 32, 1206-1225, 1993.

Schmetz, J., Pili, P., Tjemkes, S., Just, D., Kerkmann, J., Rota, S., and Ratier, A.: An introduction to Meteosat Second Generation (MSG), B. Am. Meteorol. Soc., 83, 977-992, 2002.

Schutgens, N. and Roebeling, R.: Validating the Validation: The Influence of Liquid Water Distribution in Clouds on the Intercomparison of Satellite and Surface Observations, J. Atmos. Ocean. Technol., 26, 1457-1474, 2009.

Shettle, E.: Models of aerosols, clouds and precipitation for atmospheric propagation studies, in: Atmospheric propagation in the uv, visible, ir and mm-region and related system aspects, no. 454 in AGARD Conference Proceedings, 1989.

Smith, W. and Platt, C.: Intercomparison of radiosonde, groundbased laser, and satellite-deduced cloud heights, J. Appl. Meteorol., 17, 1796-1802, 1978.

Smith, W., Woolf, H., and Jacob, W.: A regression method for obtaining real-time temperature and geopotential height profiles from satellite spectrometer measurements and its application to Nimbus-3 SIRS observations, Mon. Weather Rev., 98, 604-611, 1970.

Smith, W., Woolf, H., Abel, P., Hayden, C., Chalfant, M., and 
Grody, N.: Nimbus 5 sounder data processing system, 1, Measurement characteristics and data reduction procedures, NOAA Tech. Memo. NESS 57, Natl. Ocean. Atmos. Admin., Silver Spring, MD, USA, 1974.

Stammes, P.: Spectral radiance modelling in the UV-Visible range, in: IRS 2000: Current problems in atmospheric radiation, edited by Smith, W. and Timofeyev, Y., Proceedings of the International Radiation Symposium, A. Deepak Publishing, 385-388, 2001.

Stammes, P., Acarreta, J., Knap, W., and Tilstra, L.: Earth reflectance spectra from 300-1750 nm measured by SCIAMACHY, in: IRS 2004: Current problems in atmospheric radiation, edited by: Fischer, H. and Sohn, B.-J., Proceedings of the International Radiation Symposium, A. Deepak Publishing, 2005.

Stamnes, K., Tsay, S., Wiscombe, W., and Jayaweera, K.: A numerically stable algorithm for discrete-ordinate-method radiative transfer in multiple scattering and emitting layered media, Appl. Opt., 27, 2502-2509, 1988.

Stamnes, K., Tsay, S.-C., Wiscombe, W., and Laszlo, I.: DISORT, a General-Purpose Fortran Program for Discrete-Ordinate-Method Radiative Transfer in Scattering and Emitting Layered Media: Documentation of Methodology, Tech. rep., Dept. of Physics and Engineering Physics, Stevens Institute of Technology, Hoboken, NJ 07030, USA, 2000.

Stephens, G.: Radiation profiles in extended water clouds. II: Parameterization schemes, J. Atmos. Sci., 35, 2123-2132, 1978.

Steppeler, J., Doms, G., Schättler, U., Bitzer, H., Gassmann, A., Damrath, U., and Gregoric, G.: Meso-gamma scale forecasts using the nonhydrostatic model LM, Meteorol. Atmos. Phys., 82, 75-96, 1997.

Szejwach, G.: Determination of semi-transparent cirrus cloud temperatures from infrared radiances: Application to Meteosat, J. Appl. Meteorol., 21, 384-393, 1982.

Tartaglione, N.: Relationship between Precipitation Forecast Errors and Skill Scores of Dichotomous Forecasts, Weather Forecast., 25, 355-365, doi:10.1175/2009WAF2222211.1, 2010.
Tiedtke, M.: A comprehensive mass flux scheme for cumulus parameterisation in large scale models, Mon. Weather Rev., 117, 1779-1800, 1989.

Van Weele, M., Martin, T., Blumthaler, M., Brogniez, C., den Outer, P., Engelsen, O., Lenoble, J., Pfister, G., Ruggaber, A., Walravens, B., Weihs, P., Dieter, H., Gardiner, B., Gillotay, D., Kylling, A., Mayer, B., Seckmeyer, G., and Wauben, W.: From model intercomparisons towards benchmark UV spectra for six real atmospheric cases, J. Geophys. Res., 105, 4915-4925, 2000.

Venema, V., Garcia, S. G., and Simmer, C.: A new algorithm for the downscaling of cloud fields, Q. J. Roy. Meteorol. Soc., 136, 91-106, doi:10.1002/qj.535, 2010.

Wan, Z. and Dozier, J.: A generalized split-window algorithm for retrieving land-surface temperature from space, IEEE T. Geosci. Remote Sens., 34, 892-905, 1996.

Wan, Z. and Li, Z.-L.: A physics-based algorithm for retrieving land-surface emissivity and temperature from EOS/MODIS data, IEEE Transactions on Geoscience and Remote Sensing, 35, 980996, 1997.

Wolters, E., Roebeling, R., and Feijt, A.: Evaluation of Cloud-Phase Retrieval Methods for SEVIRI on Meteosat-8 Using GroundBased Lidar and Cloud Radar Data, J. Appl. Meteorol. Climatol., 47, 1723-1738, doi:10.1175/2007JAMC1591.1, 2008.

Woodcock, F.: The Evaluation of Yes/No Forecasts for Scientific and Administrative Purposes, Mon. Weather Rev., 104, 1209-1214, doi:10.1175/15200493(1976)104;1209:TEOYFF ¿2.0.CO;2, 1976.

Wyser, K. and Ström, J.: A possible change in cloud radiative forcing due to aircraft exhaust, Geophys. Res. Lett., 25, 1673-1676, 1998.

Yang, P., Liou, K., Wyser, K., and Mitchell, D.: Parameterization of the scattering and absorption properties of individual ice crystals, J. Geophys. Res., 105, 4699-4718, 2000.

Zinner, T. and Mayer, B.: Remote sensing of stratocumulus clouds: Uncertainty and biases due to inhomogeneity, J. Geophys. Res., 111, D14209, doi:10.1029/2005JD006955, 2006. 